\title{
An integrative approach in the assessment of species delimitation and structure of the Merodon nanus species group (Diptera: Syrphidae)
}

\section{Tubic, Natasa Kocis}

2018-12

Tubic , N K, Stahls , G , Acanski , J , Djan , M , Vidakovic , D O , Hayat, R, Khaghaninia , S , Vujic , A \& Radenkovic , S 2018, ' An integrative approach in the assessment of species delimitation and structure of the Merodon nanus species group (Diptera: Syrphidae) ' , Organisms Diversity \& Evolution , vol. 18 , no. 4 , pp. 479-497 . https://doi.org/10.1007/s13127-018-0381-7

http://hdl.handle.net/10138/307878

https://doi.org/10.1007/s13127-018-0381-7

cc_by_nd

draft

Downloaded from Helda, University of Helsinki institutional repository.

This is an electronic reprint of the original article.

This reprint may differ from the original in pagination and typographic detail.

Please cite the original version. 


\title{
An integrative approach in the assessment of species delimitation and structure of the Merodon nanus species group (Diptera: Syrphidae)
}

\author{
Nataša Kočiš Tubić ${ }^{1}$ (D) Gunilla Ståhls ${ }^{2}$ • Jelena Ačanski ${ }^{3}$ - Mihajla Djan ${ }^{1}$ • Dragana Obreht Vidaković ${ }^{4}$. \\ Rüstem Hayat $^{5}$ - Samad Khaghaninia ${ }^{6}$. Ante Vujić ${ }^{1}$ - Snežana Radenković ${ }^{1}$
}

Received: 23 March 2018 / Accepted: 20 September 2018 / Published online: 9 October 2018

(C) Gesellschaft für Biologische Systematik 2018

\begin{abstract}
The Merodon nanus group (Diptera, Syrphidae) is a small group of closely related species with high morphological similarity. Until now, based on morphological characters, this group consisted of five species: M. nanus Sack, 1931; M. telmateia Hurkmans, 1987; M. kopensis Vujić et Hayat, 2015; M. neonanus Vujić et Taylor, 2015; and M. rasicus Vujić et Radenković, 2015. Here, using an integrative approach based on molecular characters (sequences of the D2-3 region of the nuclear 28S rRNA gene and the mitochondrial COI gene) and data obtained from geometric morphometry of wing shape, we distinguish all five previously morphologically defined species of the group. Additionally, we identify one species as being new to science, $M$. vladimiri Vujić et Kočiš Tubić sp. n. We emphasize the separation of this newly described species according to the sequences obtained from the slowly evolving 28S rRNA gene, which demonstrated four to five mutation positions between this species and morphologically the most similar M. neonanus species. Also, our results show a clear division of M. telmateia into at least three population groups that we designate as the subspecies: M. telmateia mediterraneus Ačanski et Kočiš Tubić subsp. n. and $M$. telmateia samosensis Ačanski et Kočiš Tubić subsp. n. exhibiting western distributions (western Anatolia and the Greek island of Samos, respectively) and the nominative subspecies M. telmateia telmateia with an eastern Anatolian distribution.
\end{abstract}

Keywords $28 \mathrm{~S}$ rRNA gene $\cdot$ COI gene $\cdot$ Morphometric analyses $\cdot$ Wing $\cdot$ Merodon vladimirisp. n.

Electronic supplementary material The online version of this article (https://doi.org/10.1007/s13127-018-0381-7) contains supplementary material, which is available to authorized users.
Nataša Kočiš Tubić

natasa.kocis@dbe.uns.ac.rs

Gunilla Ståhls

gunilla.stahls@helsinki.fi

Jelena Ačanski

acanskijelena@gmail.com

Mihajla Djan

mihajla.djan@dbe.uns.ac.rs

Dragana Obreht Vidaković

dragana.vidakovic@ubc.ca

Samad Khaghaninia

skhaghaninia@gmail.com

Ante Vujić

ante.vujic@dbe.uns.ac.rs
Snežana Radenković

snezana.radenkovic@dbe.uns.ac.rs

1 Department of Biology and Ecology, Faculty of Sciences, University of Novi Sad, Trg Dositeja Obradovića 2, 21000, Novi Sad, Serbia

2 Zoology Unit, Finnish Museum of Natural History, University of Helsinki, PO Box 17, 00014 Helsinki, Finland

3 BioSense Institute - Research Institute for Information Technologies in Biosystems, University of Novi Sad, Dr Zorana Đinđića 1, 21000, Novi Sad, Serbia

4 Department of Forest and Conservation Sciences, University of British Columbia, \#3027 - 2424 Main Mall, Vancouver, BC V6T 1Z4, Canada

Isparta 32260, Turkey

6 Department of Plant Protection, University of Tabriz, Tabriz 51664, Iran 


\section{Introduction}

The Merodon Meigen, 1803 is species-rich genus of hoverflies (Diptera: Syrphidae), comprising more than 160 taxa distributed throughout the Palaearctic and Afrotropical regions (Ståhls et al. 2009; Vujić et al. 2011, 2016). More than 50 species are restricted to the Mediterranean region alone (Ståhls et al. 2009; Vujić et al. 2011). The phenotypic diversity, phylogenetic relationships, genetic diversity, integrative taxonomy, distributions, as well as the biogeographical and phylogeographic patterns of the Merodon genus, have been the focus of many studies over the last decade (Mengual et al. 2006; Marcos-García et al. 2007, 2011; Vujić et al. 2007, 2012, 2013b, 2016; Milankov et al. 2008a, b, 2009, 2013; Francuski et al. 2009, 2011; Ståhls et al. 2009, 2016; Radenković et al. 2011, 2018; Popović et al. 2015; Ačanski et al. 2016; Šašić et al. 2016). However, some species groups of the genus Merodon, such as that of M. nanus, have only recently received detailed attention. Until 2015, only two species of the group, M. nanus Sack, 1931 and M. telmateia Hurkmans, 1987, have been cited. Kustov (2003) provided zoogeographical analysis, revealing an Ancient Mediterranean type of distributional range for these species, that covers eastern Mediterranean (Aegean island Lesvos, Turkey, Iran) and Caucasus (Kustov 2003; Saribiyik 2003; Reemer and Smit 2007; Khaghaninia et al. 2010; Vujić et al. 2011; Ricarte et al. 2012). Vujić et al. (2011) additionally gave data on preferred adult habitats and flowers visited.

Later on, the same authors (Vujić et al. 2015) defined the $M$. nanus group, expanding it by three newly described species: M. kopensis Vujić et Hayat, 2015; M. neonanus Vujić et Taylor, 2015; and M. rasicus Vujić et Radenković, 2015. They also provided new diagnostic characters for M. nanus and $M$. telmateia species. These five closely related species were clearly separated based on morphological characters, such as the shape of the surstylus and aedeagal box in the male genitalia. Unlike the other species of the M. nanus group, $M$. telmateia possesses additional morphological characters, i.e., pale and unicolored tarsi, which clearly distinguish it from all other members of the M. nanus group.

Furthermore, distributional data accompanied with data on environmental niches analysis also supported the existence of five ecologically distinct taxa (Vujić et al. 2015). Merodon kopensis is endemic to Turkey, whereas other species from the group have ranges extending into the east, west, and south. The authors emphasized that M. telmateia occurs in two regions where it has completely different climatic preferences, indicating that it perhaps constitutes two different taxa. They also proposed applying an integrative approach, using molecular and morphometric data, to provide more insight into structuring of the M. nanus species group. Compared to some other studied groups of the genus Merodon-such as the $M$. nigritarsis group (Radenković et al. 2011; Vujić et al. 2013a) and the M. ruficornis group (Vujić et al. 2012) - the M. nanus group showed a higher level of within-group morphological similarity, potentially indicating a more recent divergence among them.

The integrative approach and the use of different sources of information in the identification, delineation, and description of taxa are widely accepted in modern taxonomy (Dayrat 2005; Will et al. 2005; Schlick-Steiner et al. 2010; Padial et al. 2010; Riedel et al. 2013; Bluemel et al. 2014; Miraldo et al. 2014). After 10 years of practice of integrative taxonomy (Goulding and Dayrat 2016), some newly published studies still highlighted the significance of using the holistic approach, e.g., benchmarking results of molecular species delimitation against morphologically well-defined taxa in highly diverse subfamily Drusinae (Insecta, Trichoptera) (Vitecek et al. 2017). A good example of applying integrative taxonomy in studies of closely related and cryptic insect species was provided by Wang et al. (2016). Based on morphology, mitochondrial DNA, and hyperspectral reflectance profiling, they inferred the boundaries of morphologically similar species of genus Bundera (Hemiptera: Cicadellidae).

In the present study, we endeavored to detect the level of congruence between taxonomic approaches based on molecular (sequences of the D2-3 region of the nuclear 28S rRNA gene and of the mitochondrial COI gene), morphometric (wing shape), and morphological characters within M. nanus species group. We also aimed to contribute to species delimitation among all available material using integrative taxonomy and to reveal the structure of the species group.

\section{Material and methods}

\section{Molecular analysis of the Merodon nanus species group}

\section{Sampling}

In total, 75 specimens of five previously morphologically defined species of the Merodon nanus species group were analyzed. Specimens were collected by a hand net and stored at $20{ }^{\circ} \mathrm{C}$ until further use. DNA voucher specimens have been deposited in FSUNS (Faculty of Sciences, University of Novi Sad, Serbia) and MZH (Zoological Museum of the Finnish Museum of Natural History, Helsinki, Finland). All samples used for molecular analysis are listed in Table S1.

\section{Laboratory methods}

DNA was extracted from two or three legs of specimens analyzed at the Laboratory of Genetics, University of Novi Sad, Serbia, using a slightly modified SDS extraction protocol (Chen et al. 2010). PCR amplifications of the D2-3 region 
of the nuclear 28S ribosomal RNA gene and the mitochondrial protein-coding cytochrome $c$ oxidase subunit I (COI) gene were generated using the primers listed in Table 1.

PCR reactions were carried out in $25 \mu$ reaction volumes and the reaction mix consisted of $1 \times$ Taq buffer (ThermoScientific, Lithuania), $2 \mathrm{mM} \mathrm{MgCl} 2,0.1 \mathrm{mM}$ of each nucleotide, $1.25 \mathrm{U}$ Taq polymerase, 5 pmol of each primer, and approximately $50 \mathrm{ng}$ DNA. Amplifications were performed in an Applied Biosystems Verity thermal cycler under the following conditions for the COIb region: initial denaturation for 2 min at $95^{\circ} \mathrm{C}, 29$ cycles of denaturation at $94{ }^{\circ} \mathrm{C}$ for $30 \mathrm{~s}, 30 \mathrm{~s}$ annealing at $49^{\circ} \mathrm{C}, 2 \mathrm{~min}$ extension at $72{ }^{\circ} \mathrm{C}$, followed by a final extension of $8 \mathrm{~min}$ at $72{ }^{\circ} \mathrm{C}$. For the other two regions (COIa region and D2-3 region of the 28S), amplification conditions were as follows: initial denaturation for $3 \mathrm{~min}$ at $94{ }^{\circ} \mathrm{C} ; 30 \mathrm{~s}$ denaturation at $94^{\circ}, 45 \mathrm{~s}$ annealing at $50{ }^{\circ} \mathrm{C}, 1 \mathrm{~min}$ extension at $72{ }^{\circ} \mathrm{C}(29$ cycles $)$; and a final extension for $8 \mathrm{~min}$ at $72{ }^{\circ} \mathrm{C}$. Amplified DNA was electrophoresed on $1.5 \%$ agarose gels for visual inspection of amplified products.

For specimens analyzed in the Zoological Museum of the Finnish Museum of Natural History, Helsinki, DNA was extracted with a NucleoSpin Tissue kit (Macherey-Nagel) and amplified using Ready-to-Go PCR beads (GE Healthcare). The same primers were used for amplification of the selected gene fragments (Table 1).

All amplification products were purified by Exonuclease I and Shrimp Alkaline Phosphatase enzymes (ThermoScientific, Lithuania) according to the manufacturer's protocol. The fragments were sequenced on an ABI3730x1 Genetic Analyzer (Applied Biosystems) at the Finnish Institute for Molecular Medicine (FIMM), Helsinki, Finland.

\section{Data analysis}

Alignment of the sequences was performed using the Clustal W algorithm (Thompson et al. 1994), as implemented in BioEdit version 7.2.5 (Hall 1999) with final adjustments by eye. Nucleotide divergences among species were calculated using uncorrected $\mathrm{p}$-distances. The sequences were clustered using maximum parsimony (MP) and maximum likelihood (ML) analyses. Parsimony analysis was run by NONA (Goloboff 1999), spawned with the aid of Winclada (Nixon
2002), using the heuristic search algorithm with 1000 random addition replicates (mult*1000), holding 100 trees per round (hold/100), maxtrees set to 100,000, and applying TBR branch swapping. The ML trees were constructed in RAxML 8.2.10 (Stamatakis 2014) in CIPRES platform (Miller et al. 2010) using the general time-reversible (GTR) evolutionary model with a gamma distribution (GTRGAMMA) (Rodriguez et al. 1990). Nodal support was estimated using nonparametric bootstrapping with 1000 replicates for both MP and ML trees. Two trees per analysis (MP and ML) were constructed: (1) for sequences of the D2-3 region of the nuclear 28S rRNA gene and (2) for the concatenated indel-free $3^{\prime}$ and $5^{\prime}$ COI sequences. As outgroups, we used Archimicrodon sp. (GenBank accession no. KU365547 for 28S, KU365419 for the COI-3' fragment and KU365483 for the COI-5' fragment); Eumerus amoenus Loew, 1848 (GenBank accession no. KU365549 for 28S, KU365421 for the COI-3' fragment, and KU365485 for the COI-5' fragment); Merodon clunipes Sack, 1913 (GenBank accession no. MH536874 for 28S, MH538348 for the COI3 ' fragment, and MH538348 for the COI-5' fragment); and Merodon spinitarsis Paramonov, 1929 (GenBank accession no. MH536875 for 28S, MH536871 for the COI-3' fragment, and LN906939 for the COI-5' fragment).

\section{Geometric morphometric analysis}

Geometric morphometric analysis of wing shape was conducted on 292 specimens of the M. nanus species group (Table S2). Specimen from FYR Macedonia, here designated as $M$. vladimiri sp. $\mathrm{n}$., was not included in wing shape analysis due to a small sample size. The right wing of each specimen was removed using microscissors and was mounted in Hoyer's medium on a microscopic slide. Wings have been labeled and archived using unique codes saved in the FSUNS collection, together with other data relevant to the specimens. High-resolution photographs of the wings were made using a Leica DFC320 video camera attached to a Leica MZ16 stereomicroscope. Twelve homologous landmarks that could be reliably identified and that represented wing shape were chosen and drawn using TpsDig 2.05 software (Rohlf 2006) (for more details, see Fig. 4). Each wing was digitized three times to estimate the measurement error.
Table 1 Universally conserved primers used in molecular analysis of this study

\begin{tabular}{lll}
\hline Primer & Sequence & Source \\
\hline 28S-F2 & 5'-AGAGAGAGTTCAAGAGTACGTG-3' & Belshaw et al. (2001) \\
28S-3DR & 5'-TAGTTCACCATCTTT CGGGTC-3' & Belshaw et al. (2001) \\
C1-J-2183 (COIb) & 5'-CAACATTTATTTTGATTTTTTGG-3' & Simon et al. (1994) \\
TL2-N-3014 (COIb) & 5'-TCCAATGCACTAATCTGCCATATTA-3' & Simon et al. (1994) \\
LCO-S-1490 (COIa) & 5'-GGTCAACAAATCATAAAGATATATTGG-3' & Folmer et al. (1994) \\
HCO-N-2198 (COIa) & 5'-TAAACTTCAGGGTGACCAAAAAAATCA-3' & Folmer et al. (1994) \\
\hline
\end{tabular}


Measurement (digitizing) error was negligible and the average landmark coordinates for each individual were used in the analyses (Arnqvist and Mårtensson 1998).

Generalized least squares Procrustes superimposition (GLS) was used to minimize nonshape variations in location, scale, and orientation of wings and also to superimpose the wings in a common coordinate system (Rohlf and Slice 1990; Zelditch et al. 2004) by employing MorphoJ v2.0 (Klingenberg 2011). Principal component analysis (PCA) was carried out on the Procrustes shape variables to reduce the dimensionality of the dataset. All further statistical analyses were conducted in the reduced space using a subset of independent principal components (PCs) that describe the highest overall classification percentage calculated in stepwise discriminant analysis (Baylac and Frieß 2005).

Sexual dimorphism was explored by multivariate analysis of variance (MANOVA). To explore wing shape variation among the taxa, discriminant function (DA) and canonical variate analyses (CVA) were employed. Also, a Gaussian naive Bayes classifier was used to delimit species boundaries based on wing shape variation without a priori-defined groups. Phenetic relationships among taxa were determined by UPGMA analysis based on squared Mahalanobis distances computed from the DA applied to wing variables and graphically represented using GenGIS v2.4.1 (Parks et al. 2013). Superimposed outline drawings produced by MorphoJ software were used to visualize differences in mean wing shape among species pairs. All statistical analyses were performed in Statistica for Windows (Dell Statistica 2015).

Correlations between Mahalanobis square distances of wing, geographic, and climatic distances were evaluated using a two-tailed Mantel test (Mantel 1976) with 10,000 permutations in the PaSSaGe software (Rosenberg and Anderson 2011). Geographic distances were calculated as the minimum distance between two taxa using QGIS (Quantum GIS Development Team 2012), while climatic distances were calculated based on Euclidean distances of the factor scores from the PCA results published in Vujić et al. (2015).

\section{Results}

\section{Molecular species delimitation and structure of the Merodon nanus species group}

The aligned and pruned $28 \mathrm{~S}$ data matrix comprised $630 \mathrm{nu}-$ cleotide characters for 77 specimens $(73$ specimens belonging to the $M$. nanus species group +4 outgroups). The number of parsimony-informative characters was 18 for the total matrix. The strict consensus MP tree (Fig. 1) separated the previously morphologically defined species of the M. nanus species group, with the exception of $M$. kopensis and M. rasicus that shared the same genotype. All the other species do not share the 28S genotype which indicated their genetic separation. A sample from FYR Macedonia (MZH S515), previously defined by morphological characters as being $M$. neonanus, did not group with other specimens of that species. This specimen separated with the highest number of mutation steps (three to five) from the other species. The MP analysis of the 28S rRNA gene revealed high congruence with the taxonomy based on morphological characters.

The combined $3^{\prime}$ and $5^{\prime}$ fragments of the COI gene dataset comprised a total of 1338 characters for 72 specimens $(68$ specimens belonging to the $M$. nanus species group +4 outgroups). The number of parsimony-informative characters was 186 for the total matrix. The concatenated COI sequences in MP analysis (Fig. 2), besides delimitation of species within the M. nanus group, discriminated specimens also according to their sampling localities (populations) and indicated a great genetic diversity within the $M$. nanus group of species. $M$. telmateia specimens were clearly divided into samples taken from Samos Island (Greece) and two Turkish regions (Isparta and Muğla). The $M$. telmateia specimens from Iran clustered with $M$. nanus specimens (but still remained separate) rather than with other M. telmateia samples. Further, insular $M$. neonanus specimens (from Samos and Chios) did not resolve with the majority of the continental samples of this species. In contrast to the $28 \mathrm{~S}$ dataset, the combined COI analyses distinguished M. kopensis from M. rasicus. The COI sequences also separated the MZH S515 sample from FYR Macedonia from the nearest $M$. neonanus samples by 14-17 mutation points. Uncorrected pairwise divergences ( $\mathrm{p}$-distance) of COI gene sequences between this specimen and all other members of the $M$. nanus group ranged from 0.7 to $1.9 \%$.

ML analysis revealed similar topologies to respective MP trees, reinforcing the species delimitation of M. nanus species group, as well as substructuring of the analyzed species in the population (Figs. S1 and S2).

\section{Geometric morphometric analysis}

Sexual dimorphism The two-way MANOVA of wing shape showed highly significant differences among species $\left(F_{88}\right.$, $\left.{ }_{1244}=11.974 ; p<0.01\right)$, sexes $\left(F_{22}, 318=9.616032 ; p<\right.$ $0.01)$, and their interaction $\left(F_{66,929}=3.806 ; p<0.01\right)$, indicating that there is sexual shape dimorphism. Due to this sexual dimorphism, we consequently analyzed male and female specimens separately.

Males Principal component analysis carried out on the Procrustes shape variables produced 20 PCs (Table S3). Stepwise discriminant analysis revealed that the all 20 PCs represented the highest overall classification percentage of male specimens to a priori-defined species. Discriminant analysis conducted on 16 PCs showed that among males all species pairs differed highly significantly in wing shape $(p<0.01)$ with 
Fig. 1 Strict consensus tree based on two equally parsimonious trees from the analysis of the D2-3 region of the 28S rRNA gene. Length $=125$ steps, consistency index $(\mathrm{CI})=0.96$, retention index $(\mathrm{RI})=0.95$. Bootstrap values $\geq 50$ are indicated near nodes. Filled circles denote unique changes, open circles nonunique

\section{Y1778 Archimicrodon sp.}

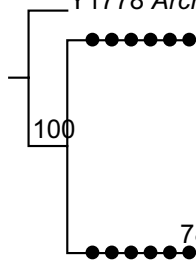

78

\section{p.}

AU736 Eumerus amoenus (IT, Sicily)

TS6 M. clunipes (TR)

$\longrightarrow$ - TS8 M. spinitarsis (TR)

- TS224 M. telmateia (TR, Isparta)

- TS223 M. telmateia (TR, Isparta)

- TS222 M. telmateia (TR, Isparta)

- TS221 M. telmateia (TR, Isparta)

- TS219 M. telmateia (TR, Isparta)

- N23 05020 M. telmateia (GR, Samos)

- GAV1724 M. telmateia (GR, Samos)

- GAV0918 M. telmateia (GR, Samos)

- MZH Y1231 M. telmateia (GR, Samos)

- MZH Y1226 M. telmateia (GR, Samos)

- MZH Y1227 M. telmateia (GR, Samos)

- MZH Y1228 M. telmateia (GR, Samos)

- MZH Y1229 M. telmateia (GR, Samos)

- MZH Y1230 M. telmateia (GR, Samos)

- AU268 M. telmateia (TR, Muğla)

- AU265 M. telmateia (TR, Muğla)

- AU264 M. telmateia (TR, Muğla)

- AU262 M. telmateia (TR, Muğla)

- AU261 M. telmateia (TR, Muğla)

- AU260 M. telmateia (TR, Muğla)

- AU259 M. telmateia (TR, Muğla)

- AU258 M. telmateia (TR, Muğla)

- AU257 M. telmateia (TR, Muğla)

- AU256 M. telmateia (TR, Muğla)

AU255 M. telmateia (TR, Muğla)

AU263 M. telmateia (TR, Muğla)

TS216 M. telmateia (IR, Kaleybar)

TS215 M. telmateia (IR, Kaleybar)

- TS214 M. telmateia (IR, Kaleybar)

- TS220 M. telmateia (TR, Isparta)

64 - TS218 M. telmateia (TR, Isparta)

- TS217 M. telmateia (TR, Isparta)

- N22 05016 M. telmateia (GR, Samos)

- GAV0919 M. telmateia (GR, Samos)

- - MZH S515 M. vladimiri sp. n. (MK, Breznica)

- GAV1839 M. rasicus (RS, Kopaonik)

- GAV1838 M. rasicus (RS, Kopaonik)

- GAV1815 M. rasicus (RS, Kopaonik)

- N18 G1824 M. rasicus (RS, Kopaonik)

- N17 G1820 M. rasicus (RS, Kopaonik)

GAV0945 M. rasicus (GR, Evros)

- AU1227 M. kopensis (TR, Askaray)

64 N19 03735 M. nanus (GR, Lesvos)

$64-N 2003734$ M. nanus (GR, Lesvos)

- MZH Y948 M. nanus (GR, Lesvos)

TS213 M. nanus (Iran)

- N13 M. neonanus (GR, Chios)

- MZH Y946 M. neonanus (GR, Chios)

- MZH Y928 M. neonanus (GR, Chios)

- MZH Y929 M. neonanus (GR, Chios)

- N12 M. neonanus (GR, Chios) $62 \quad$\begin{tabular}{lll} 
& MZH Y947 M. neonanus (GR, Chios) \\
\cline { 2 - 3 } & GAV1725 M. neonanus (GR, Samos)
\end{tabular}

62

- AU269 M. neonanus (TR, Muğla) - AU267 M. neonanus (TR, Muğla)

- AU266 M. neonanus (TR, Muğla) - AU271 M. neonanus (TR, Muğla) AU270 M. neonanus (TR, Muğla)

67 TS239 M. neonanus (TR, Isparta)

67 - TS238 M. neonanus (TR, Isparta) - TS237 M. neonanus (TR, Isparta) - TS236 M. neonanus (TR, Isparta) TS235 M. neonanus (TR, Isparta) - TS234 M. neonanus (TR, Isparta) - TS232 M. neonanus (TR, Isparta) - TS231 M. neonanus (TR, Isparta) - TS230 M. neonanus (TR, Isparta) - TS229 M. neonanus (TR, Isparta) - TS228 M. neonanus (TR, Isparta) - TS227 M. neonanus (TR, Isparta) TS226 M. neonanus (TR, Isparta) TS225 M. neonanus (TR, Isparta) 


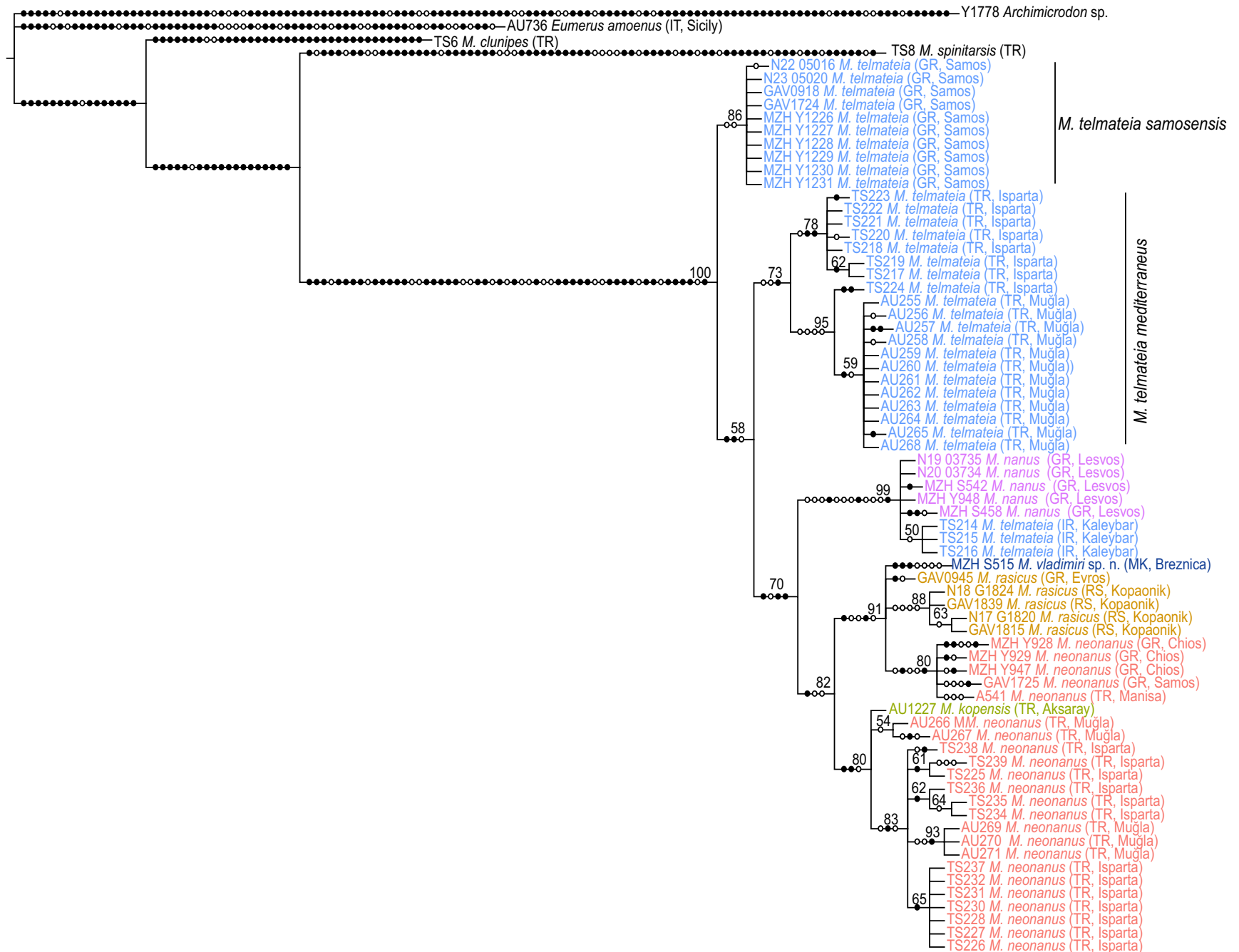

Fig. 2 Strict consensus tree based on five equally parsimonious trees from the analysis of the concatenated COI mitochondrial gene sequences. Length $=618$ steps, consistency index $(\mathrm{CI})=0.78$, retention

an overall classification success of $91.75 \%$ (Table 2). Of the 194 male specimens assessed, 16 were misclassified. Four specimens of $M$. rasicus were misclassified: two as M. nanus and two as M. telmateia. Of the 32 M. neonanus specimens, three were classified as M. kopensis. Four M. telmateia were misclassified: two as M. nanus and two as either M. neonanus or $M$. rasicus. A congruent classification was obtained by the index $(\mathrm{RI})=0.86$. Bootstrap values $\geq 50$ are indicated near nodes. Filled circles denote unique changes, open circles are nonunique changes

Gaussian naive Bayes classifier (overall classification success of $88.15 \%$ ).

Our CVA produced four highly significant canonical axes linked to shape variation among species (Table 3 ). Most of the wing shape variation (80\%) was described by CV1 and CV2. CV1 (49\% of the wing shape variation) clearly separated males of M. telmateia from M. kopensis and partially from
Table 2 Results of discriminant analysis conducted on wing shape variables. $F$ values of males are shown above the diagonal; for females, below the diagonal. $d f$ : males $=20,170 /$ females $=17$, 127

\begin{tabular}{llcccc}
\hline & M. kopensis & M.nanus & M. neonanus & M. rasicus & M. telmateia \\
\hline M. kopensis & & $12.363^{* *}$ & $5.984^{* *}$ & $10.355^{* *}$ & $17.836^{* *}$ \\
M. nanus & $/$ & & $11.258^{* *}$ & $6.307^{* *}$ & $20.061^{* *}$ \\
M. neonanus & $/$ & $4.030^{* *}$ & & $6.598^{* *}$ & $14.032^{* *}$ \\
M. rasicus & $/$ & $4.192^{* *}$ & $3.772^{* *}$ & & $7.068^{* *}$ \\
M. telmateia & $/$ & $6.756^{* *}$ & $5.621^{* *}$ & $10.523^{* *}$ & \\
\hline
\end{tabular}

**Statistically significant at $p<0.01$ 
Table 3 Results of CVA conducted on wing shape variables of species of the Merodon nanus species group

\begin{tabular}{cccccccc}
\hline CV axis & Eigenvalue & Canonical R & Wilks' lambda & Chi-square test & $d f$ & $p$ & $\begin{array}{l}\text { \% total } \\
\text { (variance) }\end{array}$ \\
\hline Males & & & & & & & \\
CV1 & 2.814175 & 0.858965 & 0.039358 & 583.9271 & 80 & 0.000000 & 49 \\
CV2 & 1.761655 & 0.798685 & 0.150119 & 342.2874 & 57 & 0.000000 & 31 \\
CV3 & 0.703672 & 0.642676 & 0.414576 & 158.9300 & 36 & 0.000000 & 13 \\
CV4 & 0.415826 & 0.541940 & 0.706302 & 62.7622 & 17 & 0.000000 & 7 \\
Females & & & & & & & \\
CV1 & 1.817900 & 0.803197 & 0.156036 & 251.7142 & 51 & 0.000000 & 64 \\
CV2 & 0.559038 & 0.598814 & 0.439694 & 111.3372 & 32 & 0.000000 & 20 \\
CV3 & 0.458791 & 0.560804 & 0.685499 & 51.1659 & 15 & 0.000008 & 16 \\
M. telmateia population analysis & & & & & \\
CV1 & 1.630226 & 0.787277 & 0.110316 & 369.2387 & 108 & 0.000000 & 51 \\
CV2 & 0.852120 & 0.678291 & 0.290155 & 207.2545 & 85 & 0.000000 & 27 \\
CV3 & 0.309479 & 0.486146 & 0.537401 & 104.0191 & 64 & 0.001161 & 10 \\
\hline
\end{tabular}

M. nanus, M. neonanus, and M. rasicus (Fig. 3a). CV2 (31\% of the wing shape variation) depicts differences between the species pairs $M$. kopensis $-M$. neonanus and $M$. nanus $-M$. rasicus (Fig. 3a). CV3 (13\% of the wing shape variation) describes differences in wing shape between $M$. kopensis and $M$. rasicus, and partially with $M$. neonanus, whereas CV4 (7\% of total wing shape variation) differentiates $M$. nanus from M. rasicus (Fig. 3b).

Based on a UPGMA phenogram from clustering of the DA-derived Mahalanobis square distances, the most similar wing shapes were between the species pairs $M$. nanus $-M$. rasicus and $M$. kopensis $-M$. neonanus, whereas $M$. telmateia had the most distinct wing shape (Fig. 4). Also, superimposed outline drawings depict the differences in mean wing shape among males of each species, which are mostly related to differences in the central and distal parts of the wing (Fig. 4).
Female Due to a small sample size, females of $M$. kopensis were not included in our wing shape analysis. Principal component analysis carried out on the Procrustes shape variables of 147 female specimens produced 20 PCs (Table S3), from which 17 represented the highest overall classification percentage of female specimens to a priori-defined species (PCs 12, 13 , and 16 were excluded by stepwise discriminant analysis).

The DA was highly significant differentiating all species pairs based on wing shape variation (Table 2) with an overall classification success of $95.24 \%$, i.e., better than for males. Only seven female specimens were misclassified and all specimens of M. nanus were correctly classified. Additionally, only five female specimens (2.72\%) were misclassified using Gaussian naive Bayes classifier.

Canonical variate analysis conducted on 17 PCs produced three highly significant axes (Table 3). CV1 (64\% of the wing
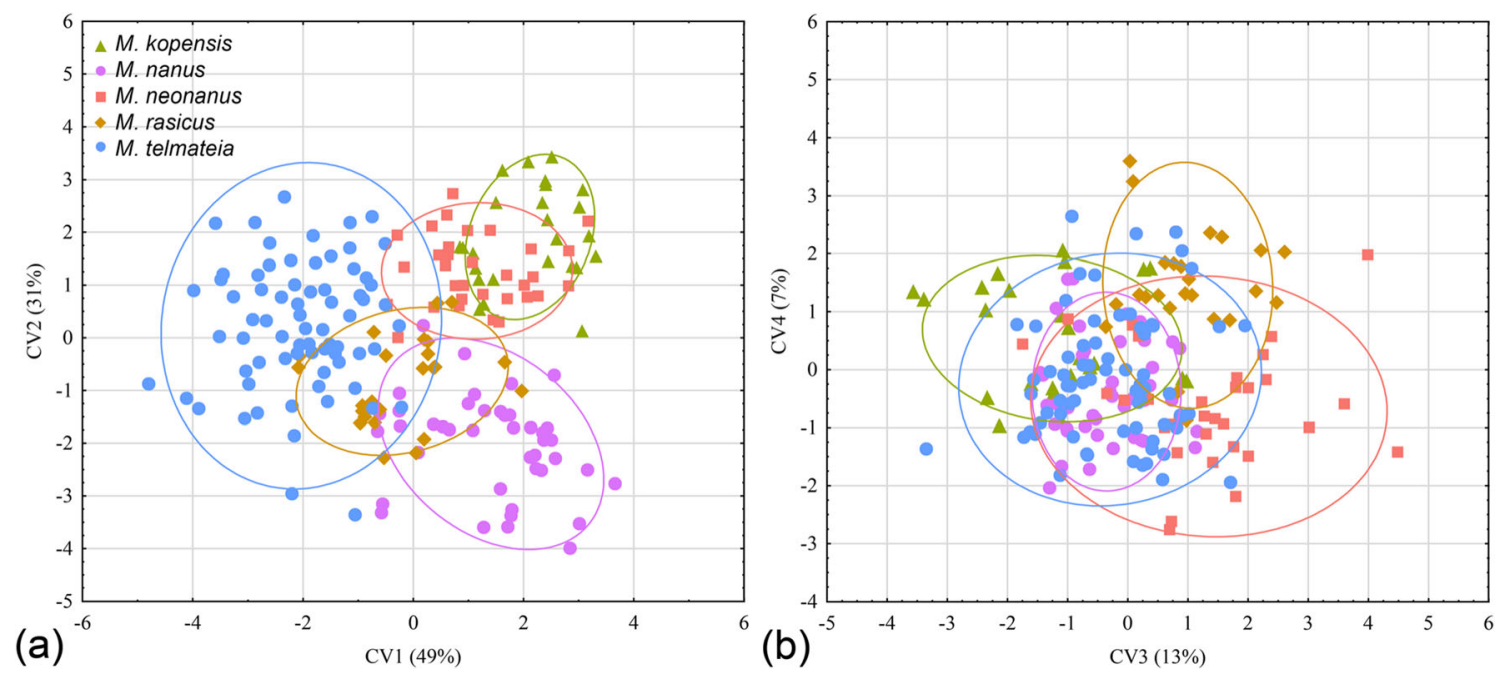

Fig. 3 Wing shape variability among male specimens of the Merodon nanus species group. a Scatter plot of individual scores of CV1 and CV2. b Scatter plot of individual scores of CV3 and CV4 


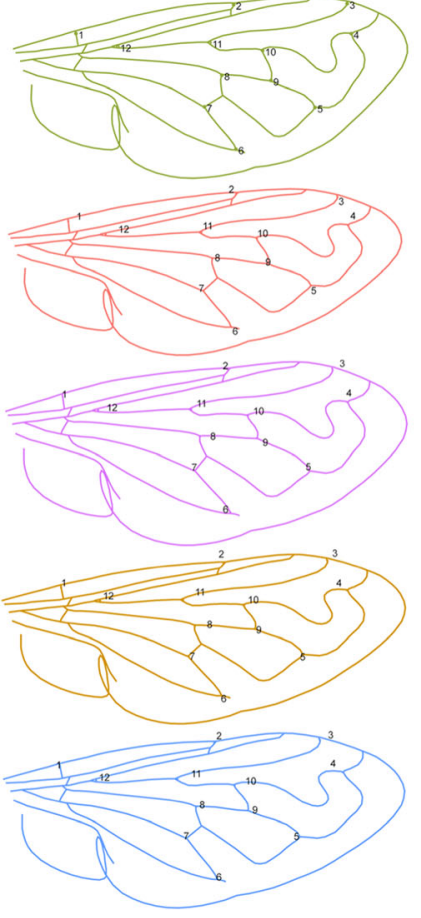

Fig. 4 Wing shape differences among male specimens of the Merodon nanus species group. UPGMA phenogram constructed using Mahalanobis square distances with superimposed outline drawings of

shape variation) differentiated the females of $M$. telmateia from all other species (Fig. 5a), whereas CV2 (20\% of the wing shape variation) clearly separated $M$. nanus from $M$. neonanus and M. rasicus (Fig. 5a). CV3 with $16 \%$ of the wing shape variation clearly separated $M$. neonanus and $M$. rasicus (Fig. 5b).

Congruent with the results of males' UPGMA analysis, females of $M$. nanus $-M$. rasicus were closest to each other, forming a branch, whereas M. telmateia and M. neonanus were in the second branch (Fig. 6). As well as in males, shape differentiation among species was linked to differences in the central and distal parts of the wing (Fig. 7). average wing shape for each species. Differences betwe
were exaggerated threefold to make them more visible

\section{Intraspecific variability of Merodon telmateia}

PCA of a total of 181 specimens of Merodon telmateia generated 18 PCs axes, and all are used in further analysis (highest overall classification percentage by stepwise discriminant analysis). The first two PCs together accounted $46 \%$ of the total variance, and although a scatter plot of PC1 vs PC2 revealed overlap between most populations, there is some indication of geographical variation among eastern and western Turkish populations (Fig. 7a). DA evidenced significant divergence between eastern and western Turkish populations, but not among eastern
Fig. 5 Wing shape variability among female specimens of the Merodon nanus species group. a Scatter plot of individual scores of CV1 and CV2. b Scatter plot of individual scores of CV1 and CV3
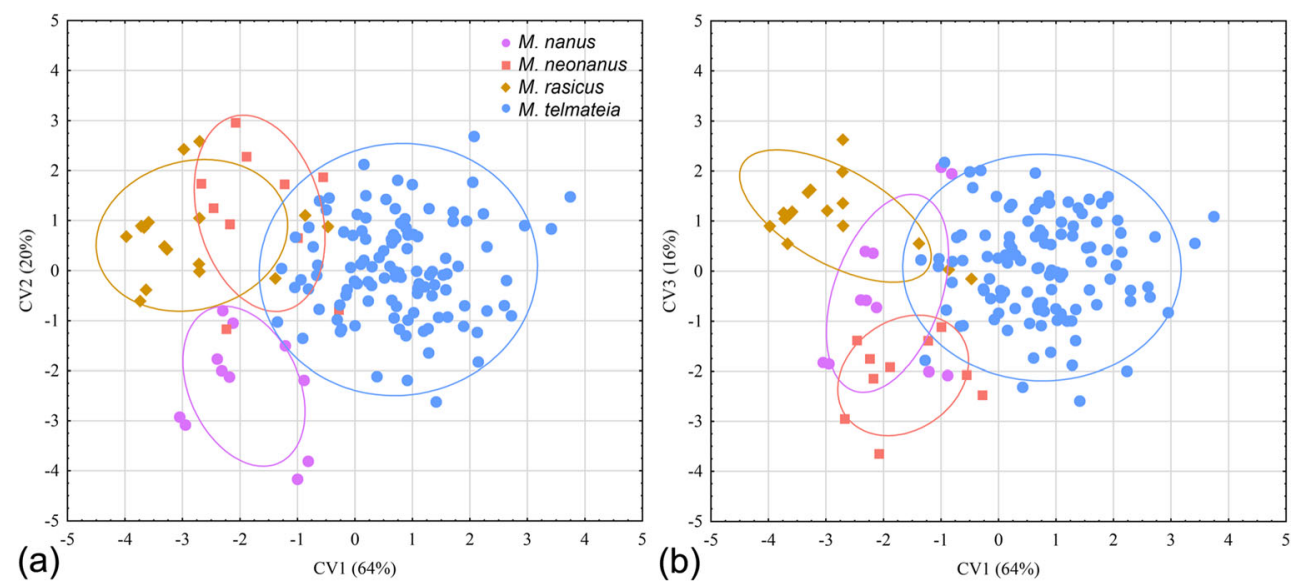


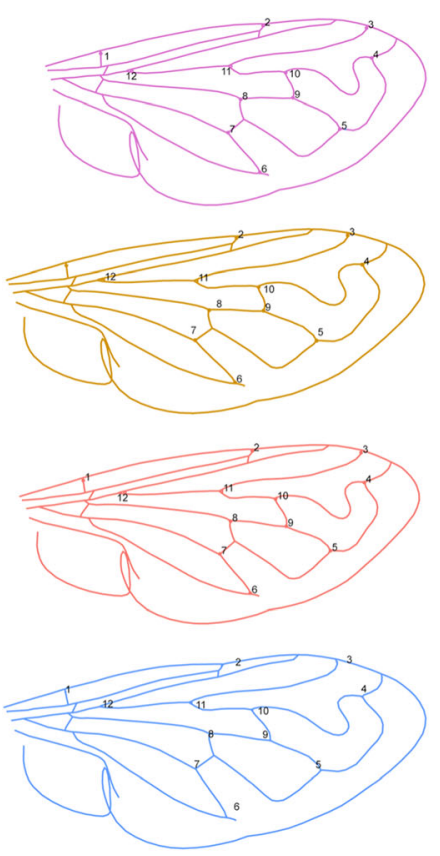

Fig. 6 Wing shape differences among female specimens of the Merodon nanus species group. UPGMA phenogram constructed using Mahalanobis square distances with superimposed outline drawings of

Turkish populations (Table 4). CVA produced three highly significant canonical axes that describe wing shape differences among the investigated populations (Table 3). The CVA plot exhibited a similar pattern to the PCA plot (Fig. 7b). CV1 (51\% of total wing shape variation) depicted wing shape differences among eastern Turkish and other conspecific populations. CV2 (27\% of total wing shape variation) distinguished Samos Island (Greece) and Iranian from Turkish populations (Fig. 7b).

UPGMA cluster analysis based on Mahalanobis square distances revealed the same population relationships depicted by CVA and DA (Fig. 8a). Eastern Turkish populations were tightly clustered, as were western Turkish populations. A population from the Greek island of Samos and an Iranian population exhibited the greatest differences from other conspecific populations. Superimposed outline drawings depict the mean wing shape of three geographically isolated populations (Samos, eastern and western Turkish populations) (Fig. 8b). Eastern Turkish specimens had the longest wings, whereas the island specimens from Samos had the shortest wings. The shape differences among these three populations are mainly associated with landmarks in the distal and basal parts of the wing (Fig. 8b).

The results of our two-tailed Mantel tests showed no association of geographic $(r=0.27240, p=0.85060)$ and environmental $(r=0.87781, p=0.14920)$ distances with wing shape distance among the investigated populations.
Fig. 7 Wing shape variability among M. telmateia populations. a Scatter plot of individual scores of PC1 and PC2. b Scatter plot of individual scores of CV1 and CV2
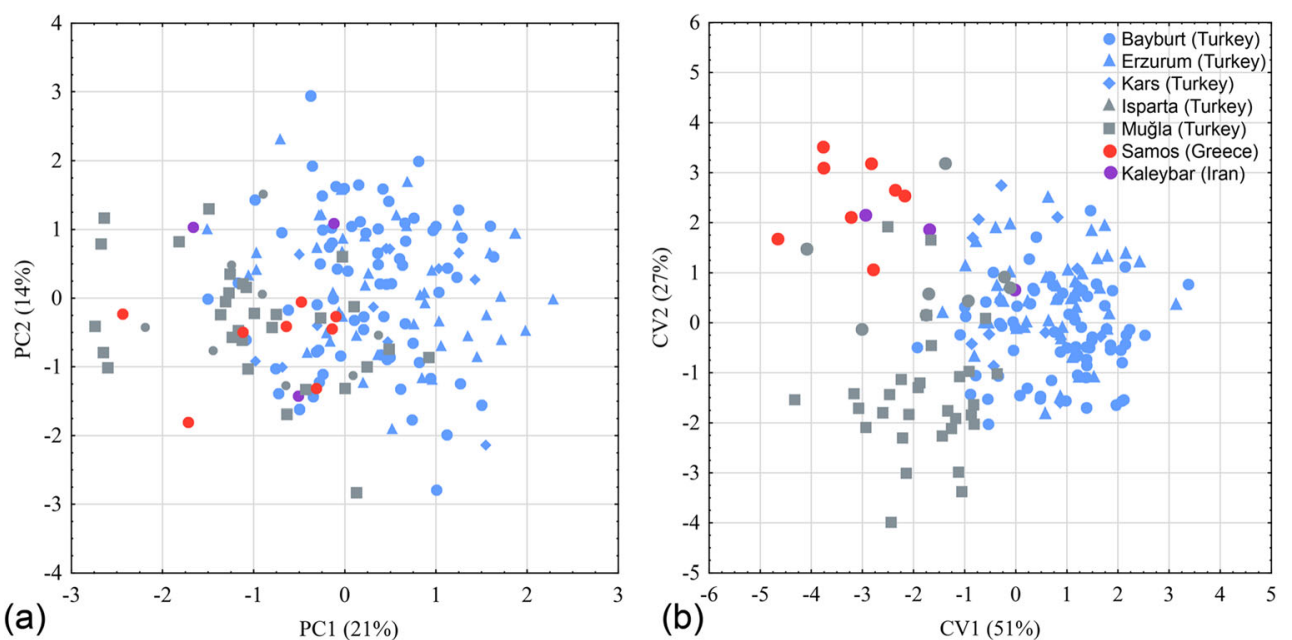
Table 4 Differences in wing shape among populations of Merodon telmateia . Below diagonal - $\mathrm{p}$ values; above diagonal $-\mathrm{F}$ values; $\mathrm{df}=18.157$

\begin{tabular}{|c|c|c|c|c|c|c|c|}
\hline & Bayburt & Erzurum & Iran & Isparta & Kars & Muğla & Samos \\
\hline Bayburt & & 2.882252 & 2.312917 & 4.107629 & 1.471600 & 9.631556 & 8.895471 \\
\hline Erzurum & $0.000209 * * *$ & & 2.109133 & 3.061827 & 1.114654 & 9.561007 & 7.584235 \\
\hline Iran & $0.003075 * *$ & $0.007740 * *$ & & 1.489601 & 1.354639 & 2.260148 & 1.486063 \\
\hline Isparta & $0.000001 * * *$ & $0.000088^{* * * *}$ & 0.100065 & & 1.867417 & 2.863697 & 2.483430 \\
\hline Kars & 0.106915 & 0.342802 & 0.161855 & $0.022170^{*}$ & & 4.133388 & 4.649369 \\
\hline Muğla & $0.000000 * * *$ & $0.000000 * * *$ & $0.003915 * *$ & $0.000229 * * *$ & $0.000000 * * *$ & & 6.157788 \\
\hline Samos & $0.000000 * * *$ & $0.000000 * * *$ & 0.101381 & $0.001394 * *$ & $0.000000 * * *$ & $0.000000 * * *$ & \\
\hline
\end{tabular}

*statistically significant at $\mathrm{p}<0.05, * *$ statistically significant at $\mathrm{p}<0.01, * * *$ statistically significant at $\mathrm{p}<0.001$

\section{Subspecies of Merodon telmateia}

Based on genetic and morphometric data, at least three groups of geographically isolated populations among Merodon telmateia specimens were identified, which we here designate as subspecies. The taxonomic position of the population from Iran remains unresolved due to a lack of available material.

\section{Merodon telmateia telmateia Ačanski (nominal subspecies)}

Diagnosis. Differs from other subspecies by morphometric wing characters (longest wing) and distribution. It is geographically separated from other populations, being distributed in northeastern Anatolia.

Type material (published in Hurkmans 1987). Holotype: Turkey: $\widehat{\alpha}$, Kars, Sarıkamıș, Kars Stream, 30 June to 5 July 1986 (RMNH).

Paratypes: Turkey: Kars: 2 2 $9,25 \mathrm{~km} \mathrm{~W}$ from Sarıkamıș, 6 June 1985 (TAU); 5 km E from Sarıkamıs, Kars Stream: ㅇ, 30 June to 5 July 1986 (NHMW); 29 9 , 30 June to 5 July 1986 (ZHMB); $\odot, 30$ June to 5 July 1986 (RMNH); $ð, 30$ June to 5 July 1986 (M.H. coll.).

Additional material: Turkey: $\hat{\delta}$, Agri, $\mathrm{N}$ from Patnos (RMNH). ㅇ Ardahan, 20 July 1977 (EMIT). Artvin: ㅇ, 5 km S from Kılıçkaya, (RMNH); Meadow above Ardanuç, 23 June
Fig. 8 Wing shape differences among M. telmateia populations. a UPGMA geo-phenogram constructed using Mahalanobis square distances. b Superimposed outline drawings of average wing shape for three groups of geographically isolated populations. Differences were exaggerated threefold to make them more visible

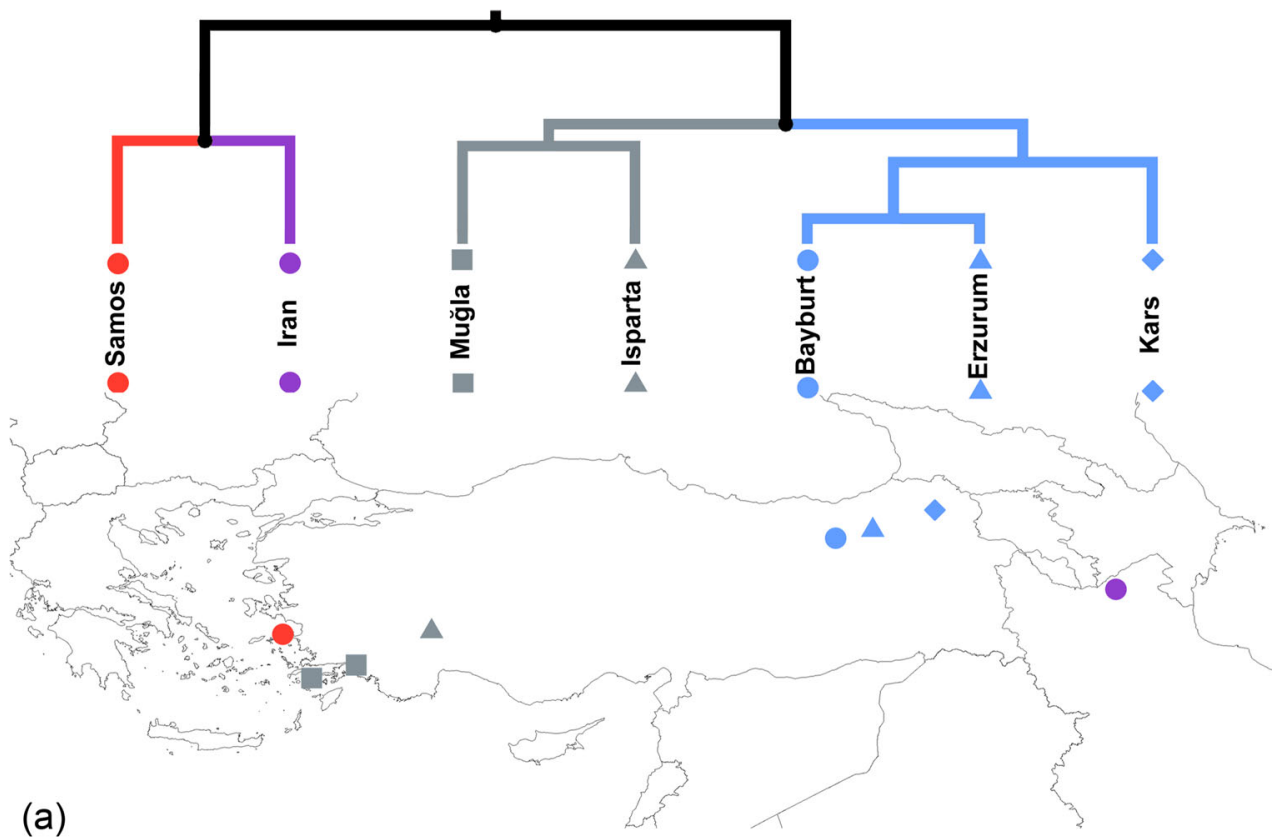

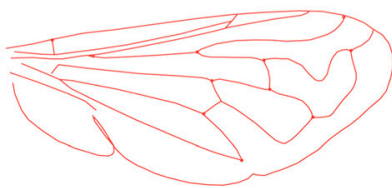

(b) M. telmateia samosensis

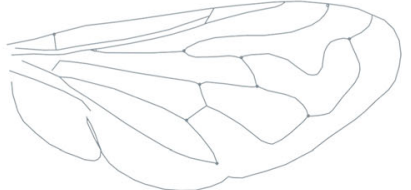

M. telmateia mediterraneus

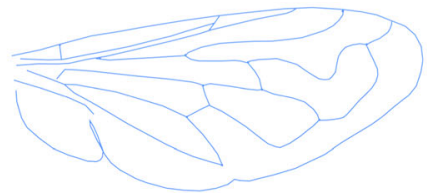

M. telmateia telmateia 
1999 (WML). Bayburt: Demirozu: 3 우, 23 July 1991 (EMIT);

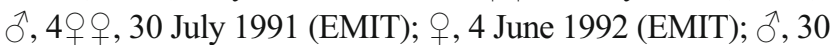
July 1991 (EMIT); ̊̊, ᄋ, Eymir Köyü, 6 Aug. 1992 (EMIT). Kop Dağı Geçidi: 12ર̂ત, 12우, 28 June 1990 (EMIT); $\partial^{\lambda}, 30$

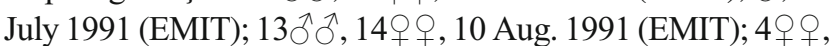

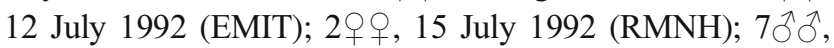

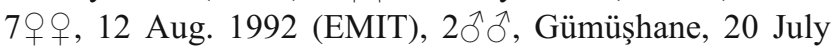

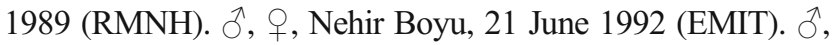

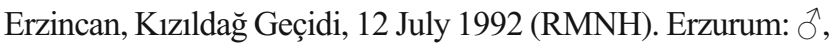
Alaybeyi köyü, 11 July 1990 (EMIT); Askale: + , 25 June 1990

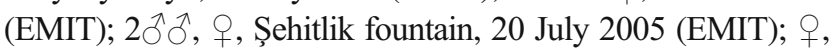
Pırnakapan, 28 June 1990 (EMIT); , Çat cimiş, 22 June 1987

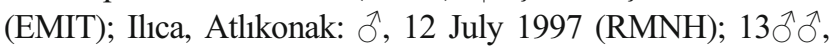
28우우, 11 June 2000 (EMIT). 2우, Karagöbek Mountain, 5 July 1989 (EMIT). , Kümbet Köyü, 11 July 1990 (EMIT). , Özbek Köyü, 11 July 1990 (EMIT). Ô, Palandöken, 17 Aug. 1988 (EMIT). đૈ, Pasinler, Rabat (RMNH). đ, Pass SW from Oltu (RMNH). Ô, Pazaryolu, 18 June 1994 (EMIT). Șenkaya: 2우, 30 July 1990 (EMIT); ô, 7 Aug. 1988 (EMIT); đ̂, 14

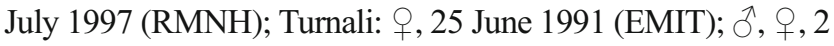
July 1990 (EMIT); 6ðð, 2우, 3 July 1990 (EMIT);,+ 20 June 1990 (EMIT). Tekman: ㅇ, 30 June 1997 (EMIT).

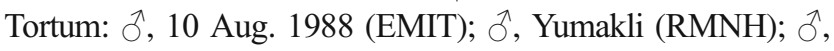
Umudum (RMNH). Kars: $\widehat{\partial}, 5 \mathrm{~km}$ E from Sarıkamış, Kars Stream (RMNH); $\hat{\jmath}, 8 \mathrm{~km} \mathrm{~W}$ from Sarıkamış (RMNH); $\hat{\partial}$, $20 \mathrm{~km}$ W from Sarıamış, Handere (RMNH); ${ }^{\lambda}$, Soganli, W from Sarikamis (RMNH); $\widehat{\partial}$, Yeniköy (RMNH). $3 \hat{\jmath} \widehat{\partial}, 8$ 우오. Rize, İkizdere, Ovit Mountaion, 29 July 2000 (EMIT).
Type locality. Turkey, Kars.

Distribution. Mountain subspecies distributed in the eastern part of the Pontic Mountains and mountains of eastern Anatolia (Fig. 9).

This is a nominotypical subspecies.

\section{Merodon telmateia samosensis Ačanski et Kočiš Tubić subsp. $\mathrm{n}$.}

Diagnosis. Differs from Merodon telmateia telmateia by morphometric wing characters (shorter and slightly narrower wing) and distribution. Molecular data show separation of $M$. telmateia samosensis from M. telmateia mediterraneus; ML and MP analyses placed these subspecies on separate branches (Figs. 2 and S2). In MP analysis of the concatenated COI sequences comprising a total of 1338 characters, 11-17 mutation positions were detected between these two subspecies (Fig. 2).

Material examined. Holotype: Greece: $\partial^{\lambda}$, Samos, near Manolates, 8 June 2010, (FSUNS).

Greece: Samos: +15 May 2010 (FSUNS). ${ }^{\lambda}$, Ambelos, near Agios Ioannis, 15 May 2010 (FSUNS). Near Manolates: + , 8 June 2010, (FSUNS); $\widehat{\alpha}, 14$ May 2010, (FSUNS); $\widehat{\partial}$, 2우, 15 May 2010, (FSUNS). §, Pyrgos, 8 June 2012 (FSUNS).

Type locality. Greece, Samos.

Distribution. Subspecies endemic to the Greek island of Samos (Fig. 9).

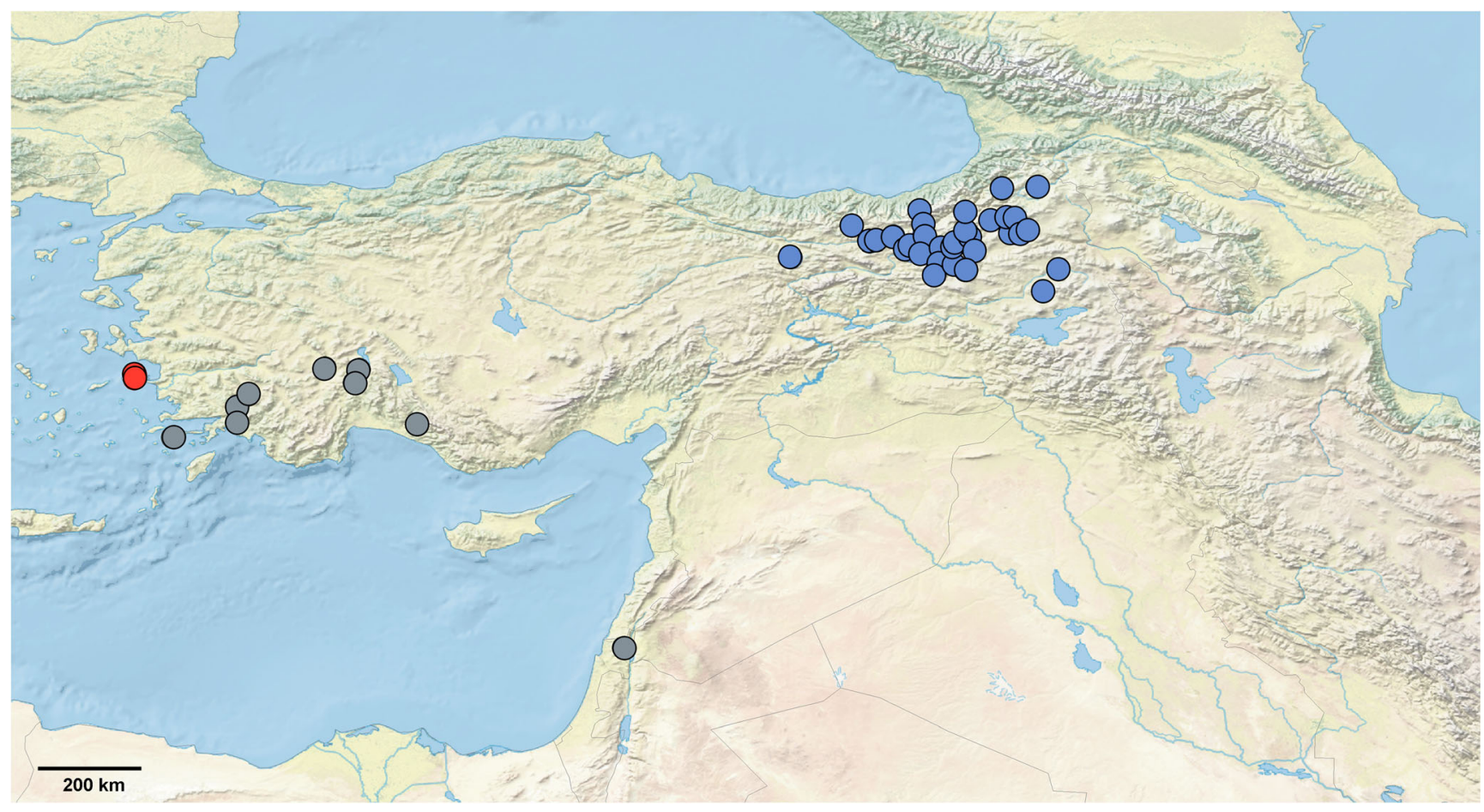

Fig. 9 Map of the eastern Mediterranean region showing the distribution of subspecies of Merodon telmateia. Red circle, M. telmateia samosensis; gray circle, M. telmateia mediterraneus; blue circle, M. telmateia telmateia 
Etymology. The name "samosensis" refers to the type locality of this endemic subspecies to the Greek Aegean island of Samos.

\section{Merodon telmateia mediterraneus Ačanski et Kočiš Tubić subsp. $\mathrm{n}$.}

Diagnosis. Differs from Merodon telmateia telmateia by morphometric wing characters (shorter and slightly wider wing) and distribution. Molecular data show separation from M. telmateia samosensis; ML and MP analyses placed these two subspecies on separate branches (Figs. 2 and S2). In the MP analysis of the concatenated COI sequences comprising a total of 1338 characters, 11-17 mutation positions were detected between $M$. telmateia mediterraneus and M. telmateia samosensis (Fig. 2).

Material examined. Holotype: Turkey: $\hat{\sigma}^{\lambda}$, Muğla, near Çakmak, 06 May 2014 (FSUNS).

Turkey: Ô, Pamphylia (Antalya), Murtiçi $25 \mathrm{~km} \mathrm{~S}$ from

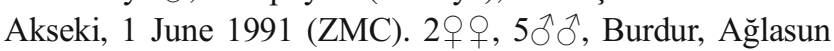
Yolu, 18 June 2015 (EMIT). +, Egirdir, Ayvalipinar koyu, 10 June 2014 (EMIT). Isparta: + , Keçiborlu Gülköy, 22 June 2015 (EMIT); ㅇ, Keçiborlu Gülköy- Kavak Arasi, 8 July 2015 (EMIT). Ô, 2 2 9 , Mermeriza, (ZHMB). Muğla:

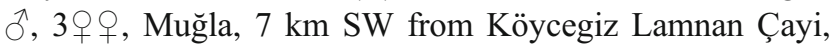
SW of Hamitköy, 1 June 2000 (M.R. coll.); đૈ, Kale, 18

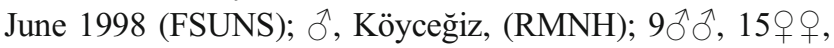
near Çakmak, 6 May 2014 (FSUNS); 3우, 6 Mar. 2014 (FSUNS). ${ }^{7}$, Reșadiye Yarimadas1, 01 June 2000 (V.W. coll.). Israel: + , Galilee, Kfar Shamai, 27 May 1980 (TAU).

Type locality. Turkey, Muğla.

Distribution. Distributed in the Aegean and Mediterranean regions of the Anatolian Peninsula as far as Israel (Fig. 9).

Etymology. The name is the Latin adjective "mediterraneus," which reflects the distribution of the subspecies in the eastern Mediterranean, from the Aegean part of the Anatolian Peninsula as far as Israel.

\section{Description of a new species}

Based on the structure of male genitalia and molecular support from analyses of nuclear 28S rRNA gene and mitochondrial COI gene sequences, specimen MZH S515 from FYR Macedonia belongs to a distinct species. Both MP and ML analytical approaches distinguished this specimen from samples of M. neonanus. MP analysis revealed 4-5 (28S sequences; Fig. 1) and 14-22 (COI sequences; Fig. 2) mutation steps between MZH S515 and M. neonanus samples, and ML trees showed this sample as a separate branch (Figs. S1 and S2). Previously, Vujić et al. (2015) described variation in the shape of the surstylus of male genitalia (Fig. 8, p. 449) and cited the possibility of it representing another cryptic taxon among $M$. neonanus. Therefore, morphological divergence, genetic characters, and its isolation from the continuous range of $M$. neonanus support recognition of a new species.

\section{Merodon vladimiri Vujić et Kočiš Tubić sp. $\mathrm{n}$.}

Diagnosis. Belongs to the $M$. nanus group and a member of the $M$. aureus clade (sensu lato) in the sense of Mengual et al. (2006). The main morphological characters are as follows: species with stocky abdomen; pilose posterior part of the mesocoxa, an area with pile on the anterior anepisternum below the postpronotum, terga with transverse fasciae of pale pile instead of pollinose fasciae (rarely with indistinct pollinosity), spike absent from the metatrochanter in male, tibiae and tarsi mostly pale except for two dark apical tarsomeres; in the male genitalia (Fig. 10), anterior surstyle lobe undeveloped; the posterior lobe of the surstylus is extremely large with a straight posterior margin, similar to $M$. neonanus (Fig. 10c: psl) but from which it differs in shape of the apical part (Fig. 10a), hypandrium broad (Fig. 10b), and aedeagal box short and broad (Fig. 10b: ae).

Description (Fig. 11).

Male. Body length $11 \mathrm{~mm}$; wing length $6 \mathrm{~mm}$.

Head. Antenna brown-orange, basoflagellomere elongated, 2.1 times as long as wide, 1.8 times longer than pedicel, with dorsal margin convex basally and concave apically; arista 1.3 times longer than the basoflagellomere. Face and frons black with bronze metallic shine, covered with long whitish-yellow pile and sparse silver white pollinosity. Oral margin shiny brown-black, well-protruded. Vertical triangle isosceles, shiny black, except for silver-gray pollinosity near eye contiguity, covered with yellow or mixed yellow and black pile; ocellar triangle equilateral or slightly isosceles. Eye contiguity 12 ommatidia long. The ratio between lengths of vertical triangle:eye contiguity:ocellar triangle (in dorsal view) $=$ 2:1:2. Eye pile dense, grayish. Occiput golden or shiny blue with whitish-yellow pile and dense white pollinosity along the eye margin.

Thorax. Mesonotum shiny black with pronounced metallic golden luster, covered with dense, erect yellow pile. Pleurae partly covered with pale pollinosity. Proepimeron, posterior anepisternum, anteroventral and posterodorsal parts of katepisternum, anepimeron, metasternum, and katatergum with long yellow pile. Wing hyaline, with dense, brown microtrichia; veins yellow-brown. Calypter bright yellow with dense long yellow marginal pile. Haltere yellow. Femora black, yellow only at tip. Metafemur not thickened, about 4.5 times as long as wide. Tibiae and tarsi yellow: tibiae with dark annulus (ring) in the middle, most expressed in the metaleg; apical two tarsomeres darkened dorsally. Pile on legs yellow, metatrochanter with a patch of short orange pile.

Abdomen. Broad and short, as long as mesonotum. Terga dark, shiny with metallic golden luster; without distinct 
Fig. 10 Male genitalia. a $M$. vladimiri sp. n., epandrium, lateral view. b $M$. vladimiri sp. n., hypandrium, lateral view. $\mathrm{c} M$. neonanus, epandrium, lateral view. psl, posterior surstyle lobe; ce, cercus; ae, aedeagal box

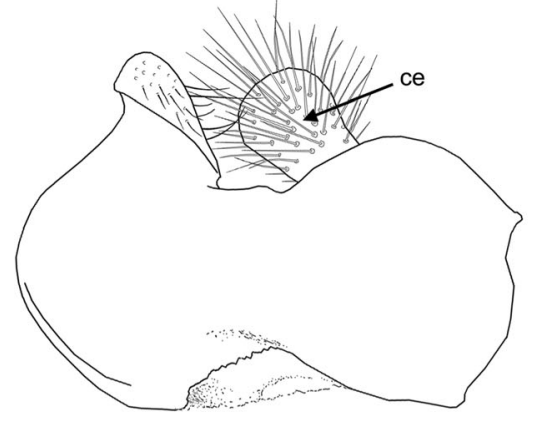

(a)

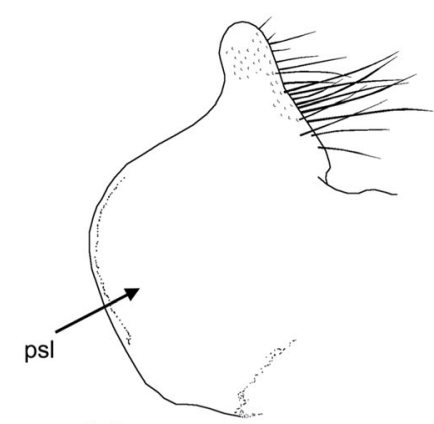

(c)

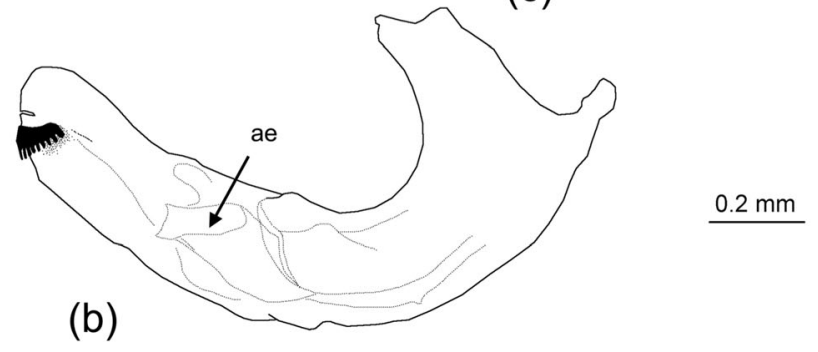

pollinose fasciae; with adpressed golden to grayish-yellow pile, except triangular black pile areas in central parts of terga 2 and 3. Sterna shiny, covered with pale pile.

Genitalia. Anterior lobe of the surstylus absent; posterior lobe of surstylus extremely large with posterior margin straight, tip narrow; ventral margin strongly S-shaped with distinct convex part of the curve (Fig. 10a); cercus rectangular, without prominences (as in Fig. 10a: ce). Hypandrium broad, curved; ctenidion situated subapically (Fig. 10b). Aedeagal box well developed with bilobate apex, short and broad, 1/4 the length of the hypandrium (Fig. 10b: ae).

Female.

Unknown.

Material examined. Holotype: FYR Macedonia: $\widehat{\jmath}$, Skopje, Breznica, 24.v.2003, leg. Krpač V. (FSUNS).

Type locality. FYR Macedonia, Skopje.

Distribution. Species distributed in the northern part of FYR Macedonia.

Etymology. The name of the species "vladimiri" is dedicated to the legator of the holotype, Vladimir Krpač, Curator of the Macedonian Museum of Natural History, Skopje, FYR Macedonia.

Fig. 11 a $M$. vladimiri sp. n., male, dorsal view (holotype). b M. telmateia, male, dorsal view (Turkey). c M. vladimiri sp. n., male, lateral view (holotype). d M. telmateia, male, lateral view (Turkey)

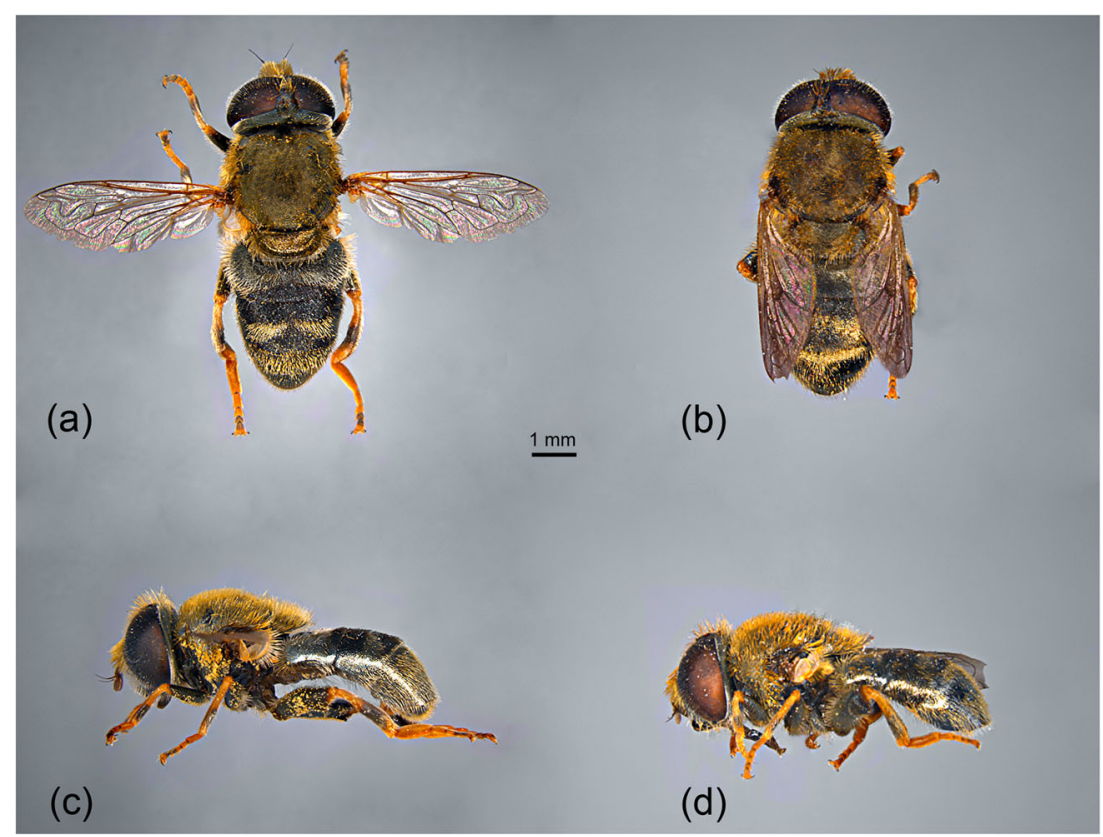

(d) 


\section{Discussion}

Using an integrative approach based on molecular characters and data obtained from geometric morphometry of wing shape, we have supported previously five morphologically defined species of the M. nanus group by Vujić et al. (2015) and detected one new species, $M$. vladimiri $\mathrm{sp}$. $\mathrm{n}$. by genetic and morphological analyses. Parsimony analysis of $28 \mathrm{~S}$ ribosomal RNA gene sequences successfully delimitated almost all analyzed species, with only one incongruity; sequences of the two species $M$. kopensis and M. rasicus were identical. However, this finding is not unusual for cryptic, closely related species, such as those of the M. nanus group (Vujić et al. 2015). In general, rRNA genes evolve more slowly than protein-encoding genes and, therefore, represent relevant molecular markers for phylogenetic analyses of distantly related species (Patwardhan et al. 2014). The D2-3 region of the nuclear 28S rRNA gene has been used to assess relationships among taxa at higher taxonomic levels, such as in family Syrphidae; for example, phylogenetic relationships of the tribe Rhingiini (Ståhls et al. 2004), of the tribe Pipizini (Vujić et al. 2013b; Mengual et al. 2015), two exceptionally speciose New World Syrphinae genera Ocyptamus Macquart, 1834 and Toxomerus Macquart, 1855 (Mengual et al. 2012), as well as tribal relationships in the subfamily Syrphinae (Mengual et al. 2008), and the general phylogeny of Syrphidae (Ståhls et al. 2003). However, this gene region, even though combined with COI gene sequences, has also proven informative for specieslevel phylogenies (e.g., Ståhls et al. 2004; Mengual et al. 2008) and even for closely related species such as those from M. ruficornis species group (Vujić et al. 2012). Here, the obtained data from 28S rRNA gene sequences of the M. nanus species group proved extremely useful, resulting in a high level of congruence with species identification based on morphological characters. The morphologically defined species (except M. kopensis and M. rasicus) were separated by one to four mutational steps to each other, while furthermore, $M$. vladimiri sp. n. showed separation with four to five mutational steps as compared to the other species (the highest number of mutational steps for 28S rRNA gene sequence within $M$. nanus group). Specimens of the M. telmateia showed two genotypes with the difference in one mutation step, but these different genotypes have no obvious overlap with the patterns of morphological differences or their distribution. A similar finding was observed for M. neonanus. All the other species within the group showed the presence of single speciesspecific genotype.

All species recognized by Vujić et al. (2015) were successfully separated based on wing shape. A high rate of correct classification for both males and females $(>90 \%)$ confirmed their clustering into species based on morphological characters and indicates that wing shape is a reliable predictor of interspecific discrimination. The importance of wing shape and its concordance with molecular and morphological data in Syrphidae taxonomy has been proven by many previous studies (Francuski et al. 2011; Nedeljković et al. 2013, 2015; Vujić et al. 2013b; Ačanski et al. 2016; Šašić et al. 2016). Furthermore, recent studies have shown that geographical distribution and environmental preferences have no impact on wing shape differences among species within the $M$. aureus and M. avidus complexes (Šašić et al. 2016; Ačanski 2017), as is expected given that insect wing shape is heritable (Bitner-Mathé and Klaczko 1999; Birdsall et al. 2000; Moraes et al. 2004; Mezey and Houle 2005; Dworkin and Gibson 2006; Yeaman et al. 2010). Differences in wing shape among male and female specimens followed similar patterns, represented by differentiation mainly in the central and distal parts of the wing. A similar pattern of wing shape variation was found in previous studies of sibling species of hoverflies, influencing wing length and width (Nedeljković et al. 2013, 2015; Vujić et al. 2013b; Ačanski et al. 2016; Šašić et al. 2016; Ačanski 2017). Variation in wing shape is species-specific and could be related to flight ability and male courtship song (Betts and Wootton 1988; Grabow and Rüppell 1995; Ritchie and Gleason 1995; Hoikkala et al. 1998; Kölliker-Ott et al. 2003; DeVries et al. 2010; Menezes et al. 2013; Outomuro et al. 2013; Sacchi and Hardersen 2013). It is interesting that male specimens of $M$. neonanus and $M$. telmateia have the most prominent changes at distal parts of the wing, influencing width and length. These two species occur sympatrically and synchronically at five localities. We hypothesize that differences in wing shape among male specimens of these two species are due to the process of reproductive isolation through courtship song. Several studies on Drosophila have shown that wing shape influences male species-specific courtship song, which is an important premating barrier (promoting sexual and reproductive isolation) (Cowling and Burnet 1981; Ritchie and Gleason 1995; Tauber and Eberl 2003; Menezes et al. 2013).

We can conclude that combination and congruence of morphology (especially of male genitalia), wing morphometry, and molecular data of $28 \mathrm{~S}$ rRNA gene allow delimitation of species within the M. nanus group.

The mitochondrial protein-coding genes, due to their faster evolutionary rates compared to rRNA genes, are regarded as powerful markers for genetic diversity analysis at lower categorical levels, including families, genera, and species. One of the most extensively used is cytochrome oxidase I (COI) gene emerging as a good strategy for species identification, delimitation, as well as for biodiversity analysis (Hwang and Kim 1999; Arif and Khan 2009). This gene is frequently applied in molecular taxonomic studies of hoverflies (see Pérez-Bañón et al. 2003; Masetti et al. 2006; Mengual et al. 2006; Milankov et al. 2008a, b; Ståhls et al. 2009; Marcos-García et al. 2011; Radenković et al. 2011, 2018; Vujić et al. 2012, 2013b; Šašić et al. 2016). The combined analysis of both fragments of COI gene in our study divided the closely related species of the $M$. 
nanus species group, including $M$. kopensis and $M$. rasicus that the $28 \mathrm{~S}$ nuclear region could not differentiate. The speciesspecific COI haplotypes were detected, i.e., there are no shared haplotypes among previously morphologically defined species of the M. nanus group by Vujić et al. (2015). In addition to species separation, the COI sequences also discriminated geographically isolated populations within species. Hence, the diversity at both the inter- and intraspecific levels was detected. The most obvious data enhancement arising from COI sequence was separation of $M$. telmateia into populations from Samos Island and western Turkey (Isparta and Muğla). This separation, which is supported by high bootstrap values (COI MP tree: 86 and 73 for Samos and Isparta-Muğla, respectively), prompted us to treat these genetic clusters as separate units. Therefore, based on strong genetic support and morphometric analysis of wing shape, as well as their disjunct distributions (without intraspecific morphological differences), we designate these populations as the subspecies M. telmateia samosensis (Samos Island) and M. telmateia mediterraneus (Isparta and Muğla). Also, we detected a very distinct genetic signal for Iranian samples, indicating potential species status for this population. However, due to a lack of genetic data for eastern Turkish populations (geographically close to Iran) because of the age of the specimens, we could not further assess the taxonomic position of this Iranian cluster. Therefore, the taxonomic status of the Iranian population remains unresolved and warrants further study. Our geometric morphometric analyses on the eastern Turkish populations clearly divided them from the western Turkish populations, and here, we designate the eastern Turkish population as a distinct subspecies M. telmateia telmateia. Overall then, we have shown clear division of $M$. telmateia into at least three subspecies: two with a western and one with an eastern distribution, supporting previous indication of the presence of substructuring (subdivision) in this taxon by Vujić et al. (2015).

The nominotypical subspecies M. telmateia telmateia has a northeastern Anatolian distribution linked to the mountains in this region. Merodon telmateia samosensis is restricted to the Greek Aegean island of Samos, whereas M. telmateia mediterraneus occurs in Aegean and Mediterranean regions of the Anatolian Peninsula as far as Israel. Despite their Anatolian distributions, M. telmateia telmateia and $M$. telmateia mediterraneus are strictly allopatric, with a gap between their distributions in the Central Anatolian region. The Anatolian Peninsula was an important refuge during the Quaternary ice ages (Hewitt 2001; Çiplak 2003; Habel et al. 2008). The western and eastern parts of this peninsula were separated in the past by a large Central Anatolian lake system that persisted cyclically until the end of the Pliocene (Kosswig 1995; Demirsoy 1996). This geographical barrier is probably responsible for the geographical separation of western and eastern Anatolian populations, leading to their allopatric differentiation. These areas represent hot spots for species of the
M. ruficornis (Vujić et al. 2011) and M. nanus (Vujić et al. 2015) species groups, as well as for many different animal and plant species (plants: Zohary 1973; Lepidoptera: Hesselbarth et al. 1995; Orthoptera: Çiplak 2003; Hymenoptera: Yildirim et al. 2014). Range expansion by M. telmateia telmateia and M. telmateia mediterraneus to the west and east, respectively, is prevented by the Anatolian Diagonal, as well as their specific climatic preferences. The Anatolian Diagonal represents a high-altitude barrier that divides eastern Anatolia from the rest of the landmass and acts as a biogeographical hindrance to many taxa (Gül 2013; Mutun 2016). Additionally, the western part of Anatolia has a warm Mediterranean climate with hot, dry summers and tepid rainy winters; eastern Anatolia is a high mountain area with a more severe climate and greater precipitation (Sesli and Denchev 2008). The prominent molecular and morphometric differentiation of the Samos Island population reflects the impact that the complex geological history of the Aegean archipelago and island isolation has had on intraspecific differentiation (Poulakakis et al. 2015). We found no correlation of geographical distance or environmental preferences with differences in wing shape within subspecies of M. telmateia. From a biogeographical point of view, these subspecies can be considered remnants of the ancestral continental species, which became separated by paleogeographical and paleoclimatic factors. Inhibition of gene flow among these populations now plays a major role in their intraspecific differentiation due to geographic isolation.

Here, we also identify one species new to science $(M$. vladimiri sp. n.), based on morphological and molecular analyses. Regarding morphological characters, Vujić et al. (2015) detected a specific shape of the surstylus of male genitalia in the specimen from FYR Macedonia (here designated as M. vladimiri sp. n.). Concerning that this observation was based on a single specimen, at that point of research, Vujić et al. (2015) did not have sufficient support for describing a new species and affiliated specimen from FYR Macedonia to the morphologically closest species M. neonanus. However, they indicated the possibility of it representing another cryptic taxon within M. neonanus. Here, the presented molecular analysis including this previously morphologically analyzed specimen from FYR Macedonia provided support to the previous assumption. The D2-3 region of the $28 \mathrm{~S}$ rRNA gene and COI gene clearly distinguished that sample from FYR Macedonia from all other M. neonanus samples. Additional support was provided by uncorrected pairwise divergences (p-distances) of the COI gene between this species and all other members of the M. nanus species group (range $=0.7$ $1.9 \%$ ). This range is concordant with the interspecific distances of some previously studied and closely related species, such as $M$. auripes and $M$. loewi within the M. ruficornis species group (Vujić et al. 2012), among species of the M. atratus species complex (Šašić et al. 2016), and among species of the genera Pipiza (Vujić et al. 2013b) and Cheilosia (Ståhls et al. 2008). We emphasize the separation according to sequences obtained from 
the slowly evolving 28S rRNA gene, which demonstrated four to five mutation positions between the Macedonian sample and other M. neonanus samples. The use of rDNA is not a new approach to molecular species identification, but many previously published studies rely on the analysis of long rDNA fragments (Monteiro et al. 2000; McClain et al. 2001; Ninet et al. 2003; Markmann and Tautz 2005; Monaghan et al. 2005; Shirouzu et al. 2007; Sonnenberg et al. 2007) or complete rDNA genes (Floyd et al. 2002; Caterino and Tishechkin 2006). However, Raupach et al. (2010) assessed the usefulness of three short expansion segments from two different rRNA genes (the V4 and $\mathrm{V} 7$ expansion segments of $18 \mathrm{~S}$ and the $\mathrm{D} 3$ expansion region of $28 \mathrm{~S}$ ). In combination with $\mathrm{COI}$ sequences, these regions showed potential for species discrimination, allowing unambiguous identification of $95 \%$ of ground beetle (Coleoptera: Carabidae) species. The species identification threshold for the rDNA markers analyzed in this study was only one base substitution, insertion, or deletion, but it was completely consistent for the taxa. Our results, in accordance with the morphological differences previously observed by Vujić et al. (2015), indicate that we have clear evidence for the presence of a new cryptic taxon within M. neonanus (designated here as M. vladimiri sp. n.). Support for its taxonomic rank is provided by the geographical isolation of the sample from FYR Macedonia relative to the continuous range of M. neonanus (Vujić et al. 2015). The Balkans and the Anatolian Peninsula represent clearly distinct regions that harbor different faunas (e.g., Oosterbroek and Arntzen 1992; Lumaret and Lobo 1996; Sfenthourakis 1996; Sindaco et al. 2000). Differences between them have been detected in Syrphidae groups of species, as well (Mengual et al. 2006; Vujić et al. 2012, 2013a, b; Popović et al. 2015).

Acknowledgments We thank John O'Brien for the English language editing.

Funding information This work was supported by the Ministry of Education, Science and Technological Development of Serbia (http:// www.mpn.gov.rs/), Grant Number 173002 (Conservation strategies for the preservation of protected and strictly protected species in Serbia-hoverflies (Insecta: Diptera: Syrphidae) as model organisms).

\section{References}

Ačanski, J. (2017). Taxonomy and distribution of the genus Merodon Meigen (Diptera: Syrphidae) in Palearctic. PhD thesis, University of Novi Sad, 209pp.

Ačanski, J., Vujić, A., Djan, M., Obreht Vidaković, D., Ståhls, G., \& Radenković, S. (2016). Defining species boundaries in the Merodon avidus complex (Diptera, Syrphidae) using integrative taxonomy, with the description of a new species. European Journal of Taxonomy, 237, 1-25. https://doi.org/10.5852/ejt.2016.237.

Arif, I. A., \& Khan, H. A. (2009). Molecular markers for biodiversity analysis of wildlife animals: a brief review. Animal Biodiversity and Conservation, 32(1), 9-17.
Arnqvist, G., \& Mårtensson, T. (1998). Measurement error in geometric morphometrics: empirical strategies to assess and reduce its impact on measures of shape. Acta Zoologica Academiae Scientiarum Hungaricae, 44, 73-96.

Baylac, M., \& Frieß, M., (2005). Fourier descriptors, Procrustes superimposition, and data dimensionality: an example of cranial shape analysis in modern human populations. In D. E. Slice (Ed.), Modern morphometrics in physical anthropology (pp. 145-165).

Belshaw, R., Lopez-Vaamonde, C., Degerli, N., \& Quicke, D. L. J. (2001). Paraphyletic taxa and taxonomic chaining: evaluating the classification of braconine wasps (Hymenoptera: Braconidae) using 28S D2-3 rDNA sequences and morphological characters. Biological Journal of the Linnean Society, 73, 411-424. https:// doi.org/10.1006/bijl.2001.0539.

Betts, C. R., \& Wootton, R. J. (1988). Wing shape and flight behaviour in butterflies (Lepidoptera: Papilionoidea and Hesperioidea): a preliminary analysis. Journal of Experimental Biology, 138, 271-288.

Birdsall, K., Zimmerman, E., Teeter, K., \& Gibson, G. (2000). Genetic variation for the positioning of wing veins in Drosophila melanogaster. Evolution and Development, 2, 16-24.

Bitner-Mathé, B. C., \& Klaczko, B. L. (1999). Size and shape heritability in natural populations of Drosophila mediopunctata: temporal and microgeographical variation. Genetica, 105, 35-42.

Bluemel, J. K., Derlink, M., Pavlovčič, P., Russo, I.-. R. M., Andrew King, R., Corbett, E., Sherrard-Smith, E., Blejec, A., Wilson, M. R., Stewart, A. J. A., Symondson, W. O. C., \& Virant-Doberlet, M. (2014). Integrating vibrational signals, mitochondrial DNA and morphology for species determination in the genus Aphrodes (Hemiptera: Cicadellidae). Systematic Entomology, 39, 304-324.

Caterino, M. S., \& Tishechkin, A. K. (2006). DNA identification and morphological description of the first confirmed larvae of Heteriinae (Coleoptera: Histeridae). Systematic Entomology, 31, 405-418.

Chen, H., Rangasamy, M., Tan, S. Y., Wang, H., \& Siegfried, B. D. (2010). Evaluation of five methods for total DNA extraction from western corn rootworm beetles. PLoS One, 5(8), e11963. https://doi. org/10.1371/journal.pone.0011963.

Çiplak, B. (2003). Distribution of Tettigoniinae (Orthoptera, Tettigoniidae) bush-crickets in Turkey: the importance of the Anatolian Taurus Mountains in biodiversity and implications for conservation. Biodiversity and Conservation, 12, 47-64.

Cowling, D. E., \& Burnet, B. (1981). Courtship songs and genetic control of their acoustic characteristics in sibling species of the Drosophila melanogaster subgroup. Animal Behaviour, 29, 924-935.

Dayrat, B. (2005). Towards integrative taxonomy. Biological Journal of the Linnean Society, 85(3), 407-415.

Dell Statistica. (2015). Dell Statistica data analysis software system, version 13. Dell Inc.

Demirsoy, A. (1996). Genel ve Türkiye Zoocoğrafyası. Ankara: Meteksan AȘ.

DeVries, P. J., Penz, C. M., \& Hill, R. I. (2010). Vertical distribution, flight behaviour and evolution of wing morphology in Morpho butterflies. Journal of Animal Ecology, 79(5), 1077-1085.

Dworkin, I., \& Gibson, G. (2006). Epidermal growth factor receptor and transforming growth factor- $\beta$ signaling contributes to variation for wing shape in Drosophila melanogaster. Genetics, 173, 1417-1431.

Floyd, R., Abebe, E., Papert, A., \& Blaxter, M. (2002). Molecular barcodes for soil nematode identification. Molecular Ecology, 11, 839-850.

Folmer, D., Black, M. B., Hoch, W., Lutz, R. A., \& Vrijehock, R. C. (1994). DNA primers for amplification of mitochondrial cytochrome oxidase subunit I from diverse metazoan invertebrates. Molecular Marine Biology and Biotechnology, 3, 294-299.

Francuski, L., Ludoški, J., Vujić, A., \& Milankov, V. (2009). Wing geometric morphometric inferences on species delimitation and intraspecific divergent units in the Merodon ruficornis group (Diptera, 
Syrphidae) from the Balkan Peninsula. Zoological Science, 26, 301308.

Francuski, L., Ludoški, J., Vujić, A., \& Milankov, V. (2011). Phenotypic evidence for hidden biodiversity in the Merodon aureus group (Diptera, Syrphidae) on the Balkan Peninsula: conservation implication. Journal of Insect Conservation, 15, 379-388.

Goloboff, P. (1999). NONA computer program. Tucuman: Published by the author.

Goulding, T. C., \& Dayrat, B. (2016). Integrative taxonomy: ten years of practice and looking into the future. Сборник трудов Зоологического музея МГУ им. М.В. Ломоносова. Archives of Zoological Museum of Lomonosov Moscow State University, 54, 116-133.

Grabow, K., \& Rüppell, G. (1995). Wing loading in relation to size and flight characteristics of European Odonata. Odonatologica, 24(2), $175-186$.

Gül, S. (2013). Ecological divergence between two evolutionary lineages of Hyla savignyi (Audouin, 1827) in Turkey: effects of the Anatolian diagonal. Animal Biology, 63(3), 285-295.

Habel, J. C., Meyer, M., El Mousadik, A., \& Schmitt, T. (2008). Africa goes Europe: the complete phylogeography of the marbled white butterfly species complex Melanargia galathea/M. lachesis (Lepidoptera: Satyridae). Organisms Diversity and Evolution, 8(2), 121-129.

Hall, T. A. (1999). BioEdit: a user-friendly biological sequence alignment editor and analysis program for windows 95/98/NT. Nucleic Acids Symposium Series, 41, 95-98.

Hesselbarth, G., Van Oorschot, H., \& Wagener, S. (1995). Die Tagfalter der Türkei. Band 2. Nymphalidae. Bocholt: Selbsterverlag Sigbert Wagener.

Hewitt, G. M. (2001). Speciation, hybrid zones and phylogeography or seeing genes in space and time. Molecular Ecology, 10(3), 537-549.

Hoikkala, A., Aspi, J., \& Suvanto, L. (1998). Male courtship song frequency as an indicator of male genetic quality in an insect species, Drosophila montana. Proceedings of the Royal Society of London B: Biological Sciences, 265(1395), 503-508.

Hurkmans, W. (1987). Merodon telmateia, a new hoverfly from Turkey (Diptera: Syrphidae). Entomologische Berichten (Amsterdam), 45, 69-70.

Hwang, U. W., \& Kim, W. (1999). General properties and phylogenetic utilities of nuclear ribosomal DNA and mitochondrial DNA commonly used in molecular systematic. Korean Journal of Parasitology, 37(4), 215-228.

Khaghaninia, S., Jafarlu, M., Khiaban, N. G., \& Askari, O. (2010). Introduction to hover flies (Diptera: Syrphidae) of sunflower and pumpkin fields in West Azerbaijan Province-Iran. Munis Entomology \& Zoology Journal, 5, 270-277.

Klingenberg, C. P. (2011). MORPHOJ: an integrated software package for geometric Morphometrics. Ver.2. 0. [Computer software and manual]. Molecular Ecology Resources, 11, 353-357.

Kölliker-Ott, U. M., Blows, M. W., \& Hoffmann, A. A. (2003). Are wing size, wing shape and asymmetry related to field fitness of Trichogramma egg parasitoids? Oikos, 100(3), 563-573.

Kosswig, C. (1995). Zoogeography of the Near East. Systematic Biology, 4(2), 49-73. https://doi.org/10.2307/sysbio/4.2.49.

Kustov, S. Y. (2003). Zoogeographical analysis of the hoverfly fauna (Diptera, Syrphidae) of the northwestern Caucasus. Entomological Review, 86, 188-196.

Lumaret, J.-P., \& Lobo, J. M. (1996). Geographic distribution of endemic dung beetles (Coleoptera, Scarabaeoidea) in the Western Palaearctic region. Biodiversity Letters, 3, 192-199.

Mantel, N. A. (1976). The detection of disease clustering and a generalized regression approach. Cancer Research, 27, 209-220.

Marcos-García, M. Á., Vujić, A., \& Mengual, X. (2007). Revision of Iberian species of the genus Merodon (Diptera: Syrphidae). European Journal of Entomology, 104, 531-572.
Marcos-García, M. Á., Vujić, A., Ricarte, A., \& Ståhls, G. (2011). Towards an integrated taxonomy of the Merodon equestris species complex (Diptera: Syrphidae) including description of a new species, with additional data on Iberian Merodon. Canadian Entomology, 143, 332-348.

Markmann, M., \& Tautz, D. (2005). Reverse taxonomy: an approach towards determining the diversity of meiobenthic organisms based on ribosomal signature sequences. Philosophical Transactions of the Royal Society B, 360, 1917-1924.

Masetti, A., Luchetti, A., Sommaggio, D., Burgio, G., \& Mantovani, B. (2006). Phylogeny of Chrysotoxum species (Diptera: Syrphidae) inferred from morphological and molecular characters. European Journal of Entomology, 103(2), 459-467. https://doi.org/10.14411/ eje.2006.059.

McClain, D. K., Li, J., \& Oliver Jr., J. H. (2001). Interspecific and geographical variation in the sequence of rDNA expansion segment D3 of Ixodes ticks (Acaria: Ixodidae). Heredity, 86, 234-242.

Menezes, B. F., Vigoder, F. M., Peixoto, A. A., Varaldi, J., \& BitnerMathé, B. C. (2013). The influence of male wing shape on mating success in Drosophila melanogaster. Animal Behaviour, 85(6), $1217-1223$.

Mengual, X., Ståhls, G., Vujić, A., \& Marcos-García, M. Á. (2006). Integrative taxonomy of Iberian Merodon species (Diptera, Syrphidae). Zootaxa, 1377, 1-26.

Mengual, X., Ståhls, G., \& Rojo, S. (2008). First phylogeny of predatory hoverflies (Diptera, Syrphidae, Syphinae) using mitochondrial COI and nuclear 28S rRNA genes: conflict and congruence with the current tribal classification. Cladistics, 24, 543-562.

Mengual, X., Ståhls, G., \& Rojo, S. (2012). Is the mega-diverse genus Ocyptamus (Diptera, Syrphidae) monophyletic? Evidence from molecular characters including the secondary structure of $28 \mathrm{~S}$ rRNA. Molecular Phylogenetics and Evolution, 62, 191-205.

Mengual, X., Ståhls, G., \& Rojo, S. (2015). Phylogenetic relationships and taxonomic ranking of pipizine flower flies (Diptera: Syrphidae) with implications for the evolution of aphidophagy. Cladistics, 31, 491-508

Mezey, J. G., \& Houle, D. (2005). The dimensionality of genetic variation for wing shape in Drosophila melanogaster. Evolution, 59, 10271038.

Milankov, V., Ståhls, G., \& Vujić, A. (2008a). Molecular diversity of populations of the Merodon ruficornis group (Diptera, Syrphidae) on the Balkan Peninsula. Journal of Zoological Systematics and Evolutionary Research, 46(2), 143-152.

Milankov, V., Ståhls, G., Stamenković, J., \& Vujić, A. (2008b). Genetic diversity of populations of Merodon aureus and M. cinereus species complexes (Diptera, Syrphidae): integrative taxonomy and implications for conservation priorities on the Balkan Peninsula. Conservation Genetics, 9, 1125-1137.

Milankov, V., Ludoški, J., Ståhls, G., Stamenković, J., \& Vujić, A. (2009). High molecular and phenotypic diversity in the Merodon avidus complex (Diptera, Syrphidae): cryptic speciation in a diverse insect taxon. Zoological Journal of the Linnean Society London, $155,819-833$.

Milankov, V., Ludoški, J., Francuski, L., Ståhls, G., \& Vujić, A. (2013). Genetic and phenotypic diversity patterns in Merodon albifrons Meigen, 1822 (Diptera: Syrphidae): evidence of intraspecific spatial and temporal structuring. Biological Journal of the Linnean Society, 110, 257-280.

Miller, M. A., Pfeiffer, W., \& Schwartz, T. (2010). Creating the CIPRES science gateway for inference of large phylogenetic trees. Gateway Computing Environments Workshop (GCE), IEEE, pp 1-8.

Miraldo, A., Krell, F.-. T., Smalén, M., Angus, R. B., \& Roslin, T. (2014). Making the cryptic visible-resolving the species complex of Aphodius fimetarius (Linnaeus) and Aphodius pedellus (de Geer) (Coleoptera: Scarabaeidae) by three complementary methods. Systematic Entomology, 39, 531-547. 
Monaghan, M. T., Balke, M., Gregory, T. R., \& Vogler, A. P. (2005). DNA-based species delineation in tropical beetles using mitochondrial and nuclear markers. Philosophical Transactions of the Royal Society B, 360, 1925-1933.

Monteiro, F. A., Wesson, D. A., Dotson, E. M., Schofield, C. J., \& Beard, C. B. (2000). Phylogeny and molecular taxonomy of the Rhodniini derived from mitochondrial and nuclear DNA sequences. American Journal of Tropical Medicine and Hygiene, 62, 460-465.

Moraes, E. M., Spressola, V. L., Prado, P. R. R., Costa, L. F., \& Sene, F. M. (2004). Divergence in wing morphology among sibling species of Drosophila buzzatii cluster. Journal of Zoological Systematics and Evolutionary Research, 42, 154-158.

Mutun, S. (2016). Review of oak gall wasps phylogeographic patterns in Turkey suggests a main role of the Anatolian diagonal. Turkish Journal of Forestry, 17, 1-6.

Nedeljković, Z., Ačanski, J., Vujić, A., Obreht, D., Djan, M., Ståhls, G., \& Radenković, S. (2013). Taxonomy of Chrysotoxum festivum Linnaeus, 1758 (Diptera: Syrphidae) - an integrative approach. Zoological Journal of the Linnean Society, 169, 84-102.

Nedeljković, Z., Ačanski, J., Djan, M., Obreht Vidaković, D., Ricarte, A., \& Vujić, A. (2015). An integrated approach to delimiting species borders in the genus Chrysotoxum Meigen, 1803 (Diptera: Syrphidae), with description of two new species. Contributions to Zoology, 84(4), 285-304.

Ninet, B., Jan, I., Bontems, O., Léchenne, B., Jousson, O., Panizzon, R., Lew, D., \& Monod, M. (2003). Identification of dermatophyte species by $28 \mathrm{~S}$ ribosomal DNA sequencing with a commercial kit. Journal of Clinical Microbiology, 41, 826-830.

Nixon, K. C. (2002). Winclada version 1.00.08, published by author, Ithaca, New York (http://www.cladistics.com).

Oosterbroek, P., \& Arntzen, J. W. (1992). Area-cladograms of circumMediterranean taxa in relation to Mediterranean palaeogeography. Journal of Biogeography, 19, 3-20.

Outomuro, D., Adams, D. C., \& Johansson, F. (2013). The evolution of wing shape in ornamented-winged damselflies (Calopterygidae, Odonata). Evolutionary Biology, 40, 300-309.

Padial, J. M., Miralles, A., De la Riva, I., \& Vences, M. (2010). The integrative future of taxonomy. Frontiers in Zoology, 7, 1-14.

Parks, D. H., Mankowski, T., Zangooei, S., Porter, M. S., Armanini, D. G., Baird, D. J., Langille, M. G. I., \& Beiko, R. G. (2013). GenGIS 2: geospatial analysis of traditional and genetic biodiversity, with new gradient algorithms and an extensible plugin framework. PLoS One, 8(7), e69885. https://doi.org/10.1371/journal.pone. 0069885.

Patwardhan, A., Ray, S., \& Roy, A. (2014). Molecular markers in phylogenetic studies - a review. Journal of Phylogenetics \& Evolutionary Biology, 2, 131. https://doi.org/10.4172/2329-9002.1000131.

Pérez-Bañón, C., Rojo, S., Ståhls, G., \& Marcos-García, M. A. (2003). Taxonomy of European Eristalinus (Diptera: Syrphidae) based on larval morphology and molecular data. European Journal of Entomology, 100, 417-428. https://doi.org/10.14411/eje.2003.064.

Popović, D., Ačanski, J., Djan, M., Obreht, D., Vujić, A., \& Radenković, S. (2015). Sibling species delimitation and nomenclature of the Merodon avidus complex (Diptera: Syrphidae). European Journal of Entomology, 112(4), 790-809. https://doi.org/10.14411/eje.2015. 100.

Poulakakis, N., Kapli, P., Lymberakis, P., Trichas, A., Vardinoyiannis, K., Sfenthourakis, S., \& Mylonas, M. (2015). A review of phylogeographic analyses of animal taxa from the Aegean and surrounding regions. Journal of Zoological Systematics and Evolutionary Research, 53(1), 18-32. https://doi.org/10.1111/jzs.12071.

Quantum GIS Development Team. (2012). Quantum GIS Geographic Information System. Version 2.12.3 Lyon [Internet]. Open Source Geospatial Foundation Project. Available: http://qgis.osgeo.org.

Radenković, S., Vujić, A., Ståhls, G., Perez-Banon, C., Petanidou, T., \& Simić, S. (2011). Three new cryptic species of the genus Merodon
Meigen (Diptera: Syrphidae) from the island of Lesvos (Greece). Zootaxa, 2735, 35-56.

Radenković, S., Šašić Zorić, L., Djan, M., Obreht Vidaković, D., Ačanski, J., Ståhls, G., Veličković, N., Markov, Z., Petanidou, T., Kočiš Tubić, N., \& Vujić, A. (2018). Cryptic speciation in the Merodon luteomaculatus complex (Diptera: Syrphidae) from the eastern Mediterranean. Journal of Zoological Systematics and Evolutionary Research, 56, 170-191. https://doi.org/10.1111/jzs. 12193.

Raupach, M. J., Astrin, J. J., Hannig, K., Peters, M. K., Stoeckle, M. Y., \& Wägele, J.-W. (2010). Molecular species identification of central European ground beetles (Coleoptera: Carabidae) using nuclear rDNA expansion segments and DNA barcodes. Frontiers in Zoology, 7, 26 http://www.frontiersinzoology.com/content/7/1/26.

Reemer, M., \& Smit, J. (2007). Some hoverfly records from Turkey (Diptera, Syrphidae). Volucella, 8, 135-146.

Ricarte, A., Nedeljković, Z., Rotheray, G. E., Yszkowski, R. M., Hancock, E. G., Watt, K., Hewitt, S. M., Horsefield, D., \& Wilkinson, G. (2012). Syrphidae (Diptera) from the Greek island of Lesvos, with description of two new species. Zootaxa, 3175, 1 23.

Riedel, A., Sagata, K., Suhardjono, Y. R., Tanzler, R., \& Balke, M. (2013). Integrative taxonomy on the fast track - towards more sustainability in biodiversity research. Frontiers in Zoology, 10, 15.

Ritchie, M. G., \& Gleason, J. M. (1995). Rapid evolution of courtship song pattern in Drosophila willistoni sibling species. Journal of Evolutionary Biology, 8(4), 463-479.

Rodriguez, F., Oliver, J. L., Marin, A., \& Medina, J. R. (1990). The general stochastic model of nucleotide substitution. Journal of Theoretical Biology, 142, 485-501. https://doi.org/10.1016/S00225193(05)80104-3.

Rohlf, F. J. (2006). TpsDig - digitize landmarks and outlines. Ver. 2.05. [Computer software and manual] Department of Ecology and Evolution, State University of New York at Stony Brook.

Rohlf, F. J., \& Slice, D. E. (1990). Extensions of the Procrustes method for the optimal superimposition of landmarks. Systematic Zoology, $39,40-59$.

Rosenberg, M. S., \& Anderson, C. D. (2011). PASSaGE: pattern analysis, spatial statistics and geographic exegesis. Version 2. Methods in Ecology and Evolution, 2(3), 229-232.

Sacchi, R., \& Hardersen, S. (2013). Wing length allometry in Odonata: differences between families in relation to migratory behaviour. Zoomorphology, 132(1), 23-32.

Saribiyik, S. (2003). Milesiinae fauna of Kahramanmaraș's Andirin town (Diptera: Syrphidae). Kastamonu Ĕ̌itim Dergisi, 11, 159-164.

Šašić, L., Ačanski, J., Vujić, A., Ståhls, G., Radenković, S., Milić, D., Vidaković, D. O., \& Djan, M. (2016). Molecular and morphological inference of three cryptic species within the Merodon aureus species group (Diptera: Syrphidae). PLoS One, 11(8), e0160001. https://doi. org/10.1371/journal.pone.0160001.

Schlick-Steiner, B. C., Steiner, F. M., Seifert, B., Stauffer, C., Christian, E., \& Crozier, R. H. (2010). Integrative taxonomy: a multisource approach to exploring biodiversity. Annual Review of Entomology, $55,421-438$.

Sesli, E., \& Denchev, C. M. (2008). Checklists of the myxomycetes, larger ascomycetes, and larger basidiomycetes in Turkey. Mycotaxon, 106, 65.

Sfenthourakis, S. (1996). A biogeographical analysis of terrestrial isopods (Isopoda, Oniscidea) from the central Aegean islands (Greece). Journal of Biogeography, 23, 687-698. https://doi.org/10.1111/j. 13652699.1996.tb00029.x.

Shirouzu, T., Hirose, D., \& Tokumasu, S. (2007). Sequence analyses of the $28 \mathrm{~S}$ rRNA gene D1/D2 region suggest Dacrymyces (Heterobasidiomycetes, Dacrymycetales) is polyphyletic. Mycoscience, 48, 388-394. 
Simon, C., Frati, F., Beckenbach, A., Crespi, B., Liu, H., \& Flook, P. (1994). Evolution, weighting and phylogenetic utility of mitochondrial gene-sequences and a compilation of conserved polymerase chain-reaction primers. Annals of the Entomological Society of America, 87, 651-701.

Sindaco, R., Venchi, A., Carpaneto, G. M., \& Bologna, M. A. (2000). The reptiles of Anatolia: a checklist and zoogeographical analysis. Biogeographia, 21-2000, 441-554.

Sonnenberg, R., Nolte, A. W., \& Tautz, D. (2007). An evaluation of LSU rDNA D1-D2 sequences for their use in species identification. Frontiers in Zoology, 4, 6.

Ståhls, G., Hippa, H., Rotheray, G., Muona, J., \& Gilbert, F. (2003). Phylogeny of Syrphidae (Diptera) inferred from combined analysis of molecular and morphological characters. Systematic Entomology, $28,433-450$

Ståhls, G., Vujić, A., Stuke, J.-. H., Doczkal, D., \& Muona, J. (2004). Phylogeny of the genus Cheilosia and the tribe Rhingiini (Diptera, Syrphidae) based on molecular and morphological characters. Cladistics, 4, 1-17.

Ståhls, G., Vujić, A., \& Milankov, V. (2008). Cheilosia vernalis (Diptera, Syrphidae) complex: molecular and morphological variability. Annales Zoologici Fennici, 45, 149-159.

Ståhls, G., Vujić, A., Pérez-Bañón, C., Radenković, S., Rojo, S., \& Petanidou, T. (2009). COI barcodes for identification of Merodon hoverflies (Diptera, Syrphidae) of Lesvos Island, Greece. Molecular Ecology Resources, 9, 1431-1438.

Ståhls, G., Vujić, A., Petanidou, T., Cardoso, P., Radenković, S., Ačanski, J., Pérez-Bañón, C., \& Rojo, S. (2016). Phylogeographic patterns of Merodon hoverflies in the eastern Mediterranean region: revealing connections and barriers. Ecology and Evolution, 6(7), 2226-2245. https://doi.org/10.1002/ece3.2021.

Stamatakis, A. (2014). RAxML version 8: a tool for phylogenetic analysis and post-analysis of large phylogenies. Bioinformatics, 30, 1312-1313. https://doi.org/10.1093/bioinformatics/btu033.

Tauber, E., \& Eberl, D. F. (2003). Acoustic communication in Drosophila. Behavioural Processes, 64(2), 197-210.

Thompson, J. D., Higgins, D. G., \& Gibson, T. J. (1994). Clustal W: improving the sensitivity of progressive multiple sequence alignment through sequence weighting, position-specific gap penalties and weigh matrix choice. Nucleic Acids Research, 22, 4673-4680.

Vitecek, S., Kučinić, M., Previšić, A., Živić, I., Stojanović, K., Keresztes, L., Bálint, M., Hoppeler, F., Waringer, J., Graf, W., \& Pauls, S. U. (2017). Integrative taxonomy by molecular species delimitation: multi-locus data corroborate a new species of Balkan Drusinae microendemics. BMC Evolutionary Biology, 17, 129. https://doi. org/10.1186/s12862-017-0972-5.

Vujić, A., Pérez-Bañón, C., Radenković, S., Ståhls, G., Rojo, S., Petanidou, T., \& Šimić, S. (2007). Two new species of the genus Merodon Meigen 1803 (Diptera: Syrphidae) from the island of
Lesvos (Greece), in the eastern Mediterranean. Annales de la Société Entomologique de France (N.S.), 43(3), 319-326.

Vujić, A., Marcos-García, M. Á., Saribiyik, S., \& Ricarte, A. (2011). New data on the Merodon Meigen 1803 fauna (Diptera: Syrphidae) of Turkey including description of a new species and changes in the nomenclatural status of several taxa. Annales de la Société Entomologique de France (N.S.), 47, 78-88.

Vujić, A., Radenković, S., Ståhls, G., Ačanski, J., Stefanović, A., Veselić, S., Andrić, A., \& Hayat, R. (2012). Systematics and taxonomy of the ruficornis group of genus Merodon Meigen (Diptera: Syrphidae). Systematic Entomology, 37, 578-602.

Vujić, A., Radenković, S., Likov, L., Trifunov, S., \& Nikolić, T. (2013a). Three new species of the Merodon nigritarsis group (Diptera: Syrphidae) from the Middle East. Zootaxa, 3640, 442-464.

Vujić, A., Ståhls, G., Ačanski, J., Bartsch, H., Bygebjerg, R., \& Stefanović, A. (2013b). Systematics of Pipizini and taxonomy of European Pipiza Fallen: molecular and morphological evidence (Diptera, Syrphidae). Zoologica Scripta, 42, 288-305.

Vujić, A., Radenković, S., Ačanski, J., Grković, A., Taylor, M., Gökhan Senol, S., \& Hayat, R. (2015). Revision of the species of the Merodon nanus group (Diptera: Syrphidae) including three new species. Zootaxa, 4006(3), 439-462. https://doi.org/10.11646/ zootaxa.4006.3.2.

Vujić, A., Petanidou, T., Tscheulin, T., Cardoso, P., Radenković, S., Ståhls, G., Baturan, Z., Mijatović, G., Rojo, S., Perez-Banon, C., Devalez, J., Andrić, A., Jovičić, S., Krašić, D., Markov, Z., Radišić, D., \& Tataris, G. (2016). Biogeographical patterns of the genus Merodon Meigen, 1803 (Diptera: Syrphidae) in islands of the eastern Mediterranean and adjacent mainland. Insect Conservation and Diversity, 9(3), 181-191. https://doi.org/10.1111/icad.12156.

Wang, Y., Nansen, C., \& Zhang, Y. (2016). Integrative insect taxonomy based on morphology, mitochondrial DNA, and hyperspectral reflectance profiling. Zoological Journal of the Linnean Society, 177, 378-394.

Will, K. W., Mishler, B. D., \& Wheeler, Q. D. (2005). The perils of DNA barcoding and the need for integrative taxonomy. Systematic Biology, 54, 844-851.

Yeaman, S., Chen, Y., \& Whitlock, M. C. (2010). No effect of environmental heterogeneity on the maintenance of genetic variation in wing shape in Drosophila melanogaster. Evolution, 64, 3398-3408.

Yildirim, E., Ljubomirov, T., \& Lelej, A. S. (2014). Overview of the distribution and biogeography of Crabronidae in Turkey (Hymenoptera: Aculeata). Journal of Insect Biodiversity, 2(3), 1-27.

Zelditch, M. L., Swiderski, D. L., Sheets, H. D., \& Fink, W. L. (2004). Geometric morphometrics for biologists: a primer. London: Elsevier Academic.

Zohary, M. (1973). Geobotanical foundations of the Middle East (Vol. 2). Stuttgart: Gustav FischerVerlag. 